FEDERAL RESERVE BANK OF SAN FRANCISCO

WORKING PAPER SERIES

\title{
Learning and Optimal Monetary Policy
}

\author{
Richard Dennis \\ Federal Reserve Bank of San Francisco \\ Federico Ravenna \\ University of California, Santa Cruz
}

July 2007

Working Paper 2007-19

http://www.frbsf.org/publications/economics/papers/2007/wp07-19bk.pdf

The views in this paper are solely the responsibility of the authors and should not be interpreted as reflecting the views of the Federal Reserve Bank of San Francisco or the Board of Governors of the Federal Reserve System. 


\title{
Learning and Optimal Monetary Policy*
}

\author{
Richard Dennis \\ Federal Reserve Bank of San Francisco \\ Federico Ravenna ${ }^{\dagger}$ \\ University of California, Santa Cruz
}

July 2007

\begin{abstract}
To conduct policy efficiently, central banks must use available data to infer, or learn, the relevant structural relationships in the economy. However, because a central bank's policy affects economic outcomes, the chosen policy may help or hinder its efforts to learn. This paper examines whether real-time learning allows a central bank to learn the economy's underlying structure and studies the impact that learning has on the performance of optimal policies under a variety of learning environments. Our main results are as follows. First, when monetary policy is formulated as an optimal discretionary targeting rule, we find that the rational expectations equilibrium and the optimal policy are real-time learnable. This result is robust to a range of assumptions concerning private sector learning behavior. Second, when policy is set with discretion, learning can lead to outcomes that are better than if the model parameters are known. Finally, if the private sector is learning, then unannounced changes to the policy regime, particularly changes to the inflation target, can raise policy loss considerably.
\end{abstract}

Keywords: Learning, Optimal Policy, Transparency

JEL Classification: E31, E52, E58.

\footnotetext{
${ }^{*}$ In addition to the editor and three anonymous referees, we thank Joshua Aizenman, Timothy Cogley, George Evans, Oscar Jorda, Ken Kletzer, David Lopez-Salido, Ulf Söderström, Carl Walsh, and John Williams for comments and suggestions. We also thank Anita Todd for editorial suggestions. The views expressed in this paper do not necessarily reflect those of the Federal Reserve Bank of San Francisco or the Federal Reserve System.

${ }^{\dagger}$ Address for correspondence: Richard Dennis: Economic Research, Mail Stop 1130, Federal Reserve Bank of San Francisco, 101 Market St, CA 94105, USA. Email: richard.dennis@sf.frb.org; Federico Ravenna: Department of Economics, University of California, Santa Cruz, CA 95064, USA. Email: fravenna@cats.ucsc.edu.
} 


\section{Introduction}

We study an economy in which households and firms must learn an equilibrium law of motion to form expectations and the central bank must learn structural parameters, such as those governing the short-run trade-off between inflation and output, to conduct policy. Using a stylized New Keynesian business cycle model as a laboratory, we investigate whether a central bank can learn to set policy optimally while updating its knowledge of the economy's structural parameters in real time, and we examine whether the need for households and firms to learn materially affects the central bank's ability to learn to set policy optimally. Focusing on realtime learning, we assess how central-bank learning affects policy loss and optimal policymaking over time and how optimal monetary policies bear on the learning process, and we examine the speed of learning.

We apply simulation methods to study real-time learning dynamics in an economy in which private agents employ variants of least-squares learning (as in Tetlow and von zur Muehlen, 2001, Orphanides and Williams, 2005 and 2006, Aoki and Nikolov, 2004, and Cogley and Sargent, 2005). The real-time learning approach refrains from assuming a stationary environment where beliefs are never updated. Further, in contrast to the E-stability literature, which focuses on asymptotic results, real-time learning allows us to study the transition path to the rational expectations equilibrium. Unlike previous studies, which have concentrated on the impact of private agents' learning on monetary policy assuming the central bank has full information, ${ }^{1}$ we consider an economy in which both private agents and the central bank must learn. In our model, although a full understanding of the economy eludes private agents and the central bank, a realistic assumption in our view, their learning focuses on different aspects of the economy. Private agents, knowing their own preference/technology parameters but needing to forecast future outcomes, must learn the economy's equilibrium law of motion, which takes the form of a vector autoregression. In contrast, the central bank, knowing its policy objectives but needing to set monetary policy, must learn the parameters in the equations that constrain its policy decision. Since both the central bank and private agents are learning, we can assess the extent to which the two learning problems interact, study the role of central-bank and private-sector learning on the policy performance, and

\footnotetext{
${ }^{1}$ For a partial overview of this literature, see Bullard and Mitra (2002) and Evans and Honkapohja (2001, 2003a, 2003b, 2006). Levin, Onatski, Williams, and Williams (2006), Levin and Williams (2003), and Levin, Wieland, and Williams (2003) study the performance of monetary policy rules when the central bank employs competing reference models. Walsh (2005) examines the welfare impact of misspecified parameters in the model the central bank uses to compute the optimal policy.
} 
examine whether private sector learning helps or hinders central-bank learning. Importantly, because the central bank endeavors to implement an optimal policy, and must learn structural parameters to do so, our analysis departs from least-squares learning and formulates centralbank learning in terms of a decreasing gain (generalized) instrumental variables estimator, similar to Evans and Honkapohja (2003a, 2003b).

A key feature of the learning process is that the central bank's parameter estimates, through their effect on monetary policy, affect economic outcomes and feed back into subsequent parameter estimates. Through this feedback, it is possible that the central bank may be unable to learn the model and that the real-time learnable equilibrium may correspond to a suboptimal policy, or simply not exist. Similarly, central-bank learning and private-agent learning may interact, with private-agent learning slowing or preventing the central bank from learning the rational expectations equilibrium. In these respects, although we do not analyze E-stability in any formal sense, we recognize that real-time learning behavior/outcomes need not converge to rational expectations (Evans and Honkapohja, 2001), and our simulations speak to this issue. Our results, however, indicate that the rational expectations equilibrium is real-time learnable, implying that the central bank can learn to set policy optimally. Moreover, the realtime learnability of the rational expectations equilibrium is robust to whether private agents are also learning, and to whether private agents employ a constant-gain or a decreasing-gain learning algorithm. ${ }^{2}$

This is not to say that private-sector learning is unimportant for policymaking. On the contrary, economic outcomes and the policy loss associated with the central bank's policy are both sensitive to learning, and in an unexpected way. Learning is slow, yet, when monetary policy is conducted under discretion, learning can distort monetary policy in ways that improve policy loss. Three important mechanisms appear to underlie this interesting result. First, when the central bank's estimate of the slope of the Phillips curve overstates the extent to which prices are rigid, then the central bank intervenes more aggressively. This more aggressive policy overstabilizes inflation and understabilizes the output gap relative to the full-information policy, thereby mitigating the magnitude of the discretionary stabilization bias (Dennis and Söderström, 2006). ${ }^{3}$ Second, the central bank will also tend to intervene more aggressively if it underestimates the elasticity of intertemporal substitution. Third,

\footnotetext{
${ }^{2} \mathrm{~A}$ caveat to this finding is that real-time learnability of the rational expectations equilibrium can require a large number of initial observations.

${ }^{3}$ Stabilization bias refers to the fact that discretionary policies overstabilize the output gap and understabilize inflation relative to fully optimal commitment policies in New Keynesian models.
} 
private-sector learning, by changing the persistence of inflation and the output gap, can assist stabilization. When only the central bank is learning, our simulations suggest that learning is detrimental more often than beneficial. However, when both the central bank and private agents are learning, with a non-negligible probability, the resulting policy loss can improve on the one obtained under discretion in the full-information economy. Of course, when agents employ decreasing-gain learning algorithms, this improvement in policy loss only occurs until the rational expectations equilibrium is learned.

Interestingly, private-sector and central-bank learning generally affect policy loss in opposite directions - worsening loss in the case of the central bank, and improving loss in the case of the private sector. This latter result does not extend to unannounced changes in the policy regime. If private agents learn using a constant-gain algorithm, then a change in the level of the natural rate is relatively innocuous in terms of its effect on policy loss. In contrast, a change in the relative weight the central bank assigns to output stabilization is less innocuous and a change in the inflation target is importantly detrimental to policy loss. In the case of an unannounced one percentage point change in the inflation target, policy loss can be raised by as much as 10 percent while the new inflation target is being learned. Finally, the degree of interest rate smoothing in the policy loss function plays an important role in many of our results.

Our paper is related to the work of Evans and Honkapohja (2003a, 2003b) who also consider an economy in which both the central bank and private agents must learn. However, where Evans and Honkapohja focus on E-stability of the rational expectations equilibrium using a model simpler than ours, we consider the real-time learnability of the optimal discretionary policy and focus on the impact of learning on policy loss, issues that cannot be fully addressed by establishing E-stability of the rational expectations equilibrium. An interesting line of research examines the importance of real-time learning dynamics when only private agents are learning. Tetlow and von zur Muehlen (2001) examine the cost of private agents having to learn a new monetary policy rule. They focus on an environment in which only private agents must learn and in which monetary policy is conducted using simple instrument rules. Aoki and Nikolov (2004) analyze how alternative rules for implementing the optimal policy affect policy loss. They consider a stylized real-time learning environment in which expectations are observable and where private agents and the central bank share the same model and solve the same estimation problem. In contrast, we use a more realistic learning environment, and can examine the impact of private-sector and central-bank learning on the policy performance. 
Orphanides and Williams (2006) study a model with adaptive learning by households and firms and show that monetary policies designed to be efficient under rational expectations can perform poorly when knowledge is imperfect. They find that the costs of learning can be mitigated if the central bank adopts an explicit numerical inflation target, consistent with our findings. Finally, Ferrero (2007) uses a simple forward-looking New Keynesian model to analyze the speed of learning. Unlike our study, Ferrero (2007) assumes that the central bank conducts policy using a simple instrument rule and that only private agents must learn.

The remainder of the paper is structured as follows. Section 2 introduces the New Keynesian business cycle model that we employ, presents the central bank's loss function, and describes how monetary policy would be implemented if all agents had full information and formed expectations rationally. Section 3 describes how agents learn and investigates realtime learnability of the rational expectations equilibrium, and hence of the optimal monetary policy, when the central bank and private agents are both learning. Section 3 also shows that the central bank can achieve a smaller policy loss when learning than if the model is known, a striking result that is possible because policy is set with discretion. The importance of private-agent learning is emphasized in Sections 4 and 5. In Section 4 we show that the improvements in policy loss found in Section 3 stem largely from the fact that private agents are learning. Section 6 investigates the effect on policy loss of private agents having to relearn following changes to the natural rate, the inflation target, and the relative weight the central bank attaches to output stabilization. Section 7 concludes.

\section{The model}

We study a New Keynesian business cycle model of the form widely used in the monetary policy literature. In addition to a central bank, the economy is populated by households and firms, whose behavior is summarized by

$$
\begin{aligned}
x_{t} & =\delta x_{t-1}+(1-\delta) \mathrm{E}_{t} x_{t+1}+\phi\left[i_{t}-\mathrm{E}_{t}\left(\pi_{t+1}-\bar{\pi}\right)-\bar{r}\right]+g_{t}, \\
\pi_{t}-\bar{\pi} & =\theta\left(\pi_{t-1}-\bar{\pi}\right)+(1-\theta) \beta \mathrm{E}_{t}\left(\pi_{t+1}-\bar{\pi}\right)+\lambda x_{t}+u_{t},
\end{aligned}
$$

where $x_{t}, \pi_{t}$, and $i_{t}$ are the output gap, inflation, and the nominal interest rate, respectively, $g_{t}$ is a demand shock, $u_{t}$ is a supply shock, $\bar{\pi}$ is the inflation target, and $\bar{r}$ is the natural rate of interest. The lagged output gap term in equation (1) is motivated by (external) habit formation while the lag of inflation in equation (2) can be derived as the outcome of inflation indexation, as in Smets and Wouters (2003) or Galí and Gertler (1999). Formal derivations 
of the output gap equation can be found in McCallum and Nelson (1999) and Amato and Laubach (2004). With regard to the inflation equation, the environment that gives rise to this Phillips curve is one in which firms are monopolistically competitive and in which price rigidities and inflation indexation by non-optimizing firms lead to relative price distortions. While the underlying theory implies that real marginal costs should be the driving variable in the Phillips curve, we take the approach of Clarida, Galí, and Gertler (1999) and proxy real marginal costs with the output gap. The economy's resource constraint equates consumption to output. We assume that the supply shock and the demand shock are independent, white noise processes, with finite absolute moments. We further assume that the model parameters satisfy $\{\delta, \theta, \beta\} \in(0,1), \phi \in(-\infty, 0)$, and $\lambda \in(0, \infty)$.

Equations (1) and (2) are intended to serve only as a stylized description of an economy, yet they encompass several widely studied New Keynesian models. When $\delta=0$, equation (1) collapses to the standard (log-linearized) time-separable consumption Euler equation. When $\theta=1$, equation (2) corresponds to a backward-looking accelerationist Phillips curve (Ball, 1999), and when $\theta=0$, equation (2) simplifies to the traditional Calvo-pricing specification (Calvo, 1983). Further, if $\theta=0$ and $\beta=1$, then equation (2) is equivalent to the costly priceadjustment specification of Rotemberg (1982). Intermediate values of $\theta$ closely approximate Phillips curves with full inflation indexation (Christiano, Eichenbaum, and Evans, 2005) and partial inflation indexation (Smets and Wouters, 2003).

The central bank is assumed to choose the nominal interest rate, $i_{t}$, to minimize the loss function:

$$
\mathrm{E}_{t} \sum_{j=0}^{\infty} \beta^{j}\left[\left(\pi_{t+j}-\bar{\pi}\right)^{2}+\alpha x_{t+j}^{2}+\nu\left(\Delta i_{t+j}\right)^{2}\right],
$$

subject to the behavior of households and firms, as given by equations (1) and (2). This loss function describes a central bank that aims to stabilize inflation and the output gap without making large changes in the nominal interest rate. With the weight on inflation stabilization normalized to one, the relative weight on output stabilization is $\alpha, \alpha \in[0, \infty)$, and the relative weight on interest rate smoothing is $\nu, \nu \in(0, \infty)$. Equation (3) is widely used to summarize central bank objectives as it broadly reflects the goals associated with inflation targeting (Svensson, 1997). Although the weights $\alpha$ and $v$ in the loss function can be derived from explicit microfoundations in a number of models (Woodford, 2003), we take them as parameters describing the central bank's objectives and study the implications of alternative parameterizations. 
To parameterize the model, we set $\delta$ equal to 0.50 and $\theta$ equal to 0.30 . With these values, output and inflation are persistent but consumption smoothing and the forward-looking aspect of price-setting remain prominent. The discount factor, $\beta$, is set to 0.99 , while the inflation target, $\bar{\pi}$, and the natural rate of interest, $\bar{r}$, are set to zero. Two parameters that are central in our analysis are $\phi$ and $\lambda$. In our simulations we set $\phi$ equal to -0.60 and $\lambda$ equal to 0.40 . For the policy parameters $\alpha$ and $\nu$, we consider a range of possibilities to assess whether the policy implemented by the central bank has any appreciable effect on learning dynamics. For the benchmark parameterization, however, we set $\alpha$ to 1.00 and $\nu$ to 0.50 . Finally, we set the standard deviations of the demand and supply shocks equal to 0.50 .

\subsection{Solution with rational expectations}

We assume the monetary authority cannot commit to an announced policy and that it implements a time-consistent, or optimal discretionary, policy. Although the optimal policy under commitment improves policy loss relative to the time-consistent policy, it is not implementable unless a commitment mechanism is in place, a point first made by Kydland and Prescott (1977). To solve the model, we employ the procedures developed in Dennis (2007) to solve for the first-order condition associated with the optimal discretionary policy. This first-order condition is labeled a "specific targeting rule" in Svensson and Woodford (2005). However, since the weight on the interest rate smoothing objective in the loss function is nonzero, this specific targeting rule also involves the policy instrument $i_{t}$, allowing it to be interpreted as an implicit instrument rule. A key feature of this targeting rule is that it is expressed in terms of endogenous variables and excludes the shocks, $u_{t}$ and $g_{t}$. Consequently, as Giannoni and Woodford (2005) highlight, the targeting rule that we study is invariant, or robust, to misspecification of the shock processes; such rules are also known as robust optimal explicit (ROE) rules.

To obtain the ROE rule when monetary policy is conducted with discretion, we first write the model in the second-order structural form

$$
\mathbf{A}_{0} \mathbf{y}_{t}=\mathbf{A}_{1} \mathbf{y}_{t-1}+\mathbf{A}_{2} \mathrm{E}_{t} \mathbf{y}_{t+1}+\mathbf{A}_{3} \mathbf{u}_{t}+\mathbf{A}_{4} \mathbf{v}_{t}
$$

where $\mathbf{y}_{t}$ is an $n \times 1$ vector containing the endogenous variables, $\mathbf{u}_{t}$ is a $p \times 1$ vector containing the policy instruments, $\mathbf{v}_{t}, \mathbf{v}_{t} \sim i i d[\mathbf{0}, \boldsymbol{\Omega}]$, is an $s \times 1,0<s \leq n$, vector of innovations, and $\mathbf{A}_{0}, \mathbf{A}_{1}, \mathbf{A}_{2}, \mathbf{A}_{3}$, and $\mathbf{A}_{4}$ are matrices with dimensions conformable with $\mathbf{y}_{t}, \mathbf{u}_{t}$, and $\mathbf{v}_{t}$ that contain the structural parameters. The dating of the variables is such that any variable that 
enters $\mathbf{y}_{t-1}$ is predetermined, i.e., known at the beginning of period $t$.

Next we write the policy loss function in the form

$$
L=\mathrm{E}_{0} \sum_{t=0}^{\infty} \beta^{t}\left[\mathbf{y}_{t}^{\prime} \mathbf{W} \mathbf{y}_{t}+\mathbf{u}_{t}^{\prime} \mathbf{Q} \mathbf{u}_{t}\right],
$$

where $\mathbf{W}(n \times n)$ and $\mathbf{Q}(p \times p)$ are matrices containing policy weights and are symmetric positive semi-definite, and symmetric positive definite, respectively.

The problem described by equations (4) and (5), which exploits our assumption that $\bar{\pi}=\bar{r}=0$, conforms to the class of dynamic optimization problems studied and solved by Dennis (2007). For our purposes, the key result in Dennis (2007) is that the first-order condition for the optimal discretionary policy can be written as

$$
\frac{\partial L}{\partial \mathbf{u}_{t}}=\mathbf{Q} \mathbf{u}_{t}+\mathbf{A}_{3}^{\prime} \mathbf{D}^{\prime-1} \mathbf{P} \mathbf{y}_{t}=\mathbf{0}
$$

where $\mathbf{D}$ and $\mathbf{P}$ satisfy

$$
\begin{aligned}
& \mathbf{D} \equiv \mathbf{A}_{0}-\mathbf{A}_{2} \mathbf{H} \\
& \mathbf{P} \equiv \mathbf{W}+\beta \mathbf{F}_{1}^{\prime} \mathbf{Q F}_{1}+\beta \mathbf{H}^{\prime} \mathbf{P} \mathbf{H}
\end{aligned}
$$

and where $\mathbf{y}_{t}$ and $\mathbf{u}_{t}$ evolve (in the time-consistent equilibrium) according to

$$
\begin{aligned}
& \mathbf{y}_{t}=\mathbf{H} \mathbf{y}_{t-1}+\mathbf{G v}_{t}, \\
& \mathbf{u}_{t}=\mathbf{F}_{1} \mathbf{y}_{t-1}+\mathbf{F}_{2} \mathbf{v}_{t} .
\end{aligned}
$$

Importantly, because this procedure yields the first-order condition for the optimal discretionary policy, we can assume that the central bank implements an ROE policy, rather than a state-contingent instrument rule policy, obtaining the time-consistent equilibrium by solving for the rational expectations equilibrium of the system:

$$
\left[\begin{array}{cc}
\mathbf{A}_{0} & -\mathbf{A}_{3} \\
\mathbf{A}_{3}^{\prime} \mathbf{D}^{\prime-1} \mathbf{P} & \mathbf{Q}
\end{array}\right]\left[\begin{array}{l}
\mathbf{y}_{t} \\
\mathbf{u}_{t}
\end{array}\right]=\left[\begin{array}{cc}
\mathbf{A}_{1} & \mathbf{0} \\
\mathbf{0} & \mathbf{0}
\end{array}\right]\left[\begin{array}{l}
\mathbf{y}_{t-1} \\
\mathbf{u}_{t-1}
\end{array}\right]+\left[\begin{array}{cc}
\mathbf{A}_{2} & \mathbf{0} \\
\mathbf{0} & \mathbf{0}
\end{array}\right] \mathrm{E}_{t}\left[\begin{array}{c}
\mathbf{y}_{t+1} \\
\mathbf{u}_{t+1}
\end{array}\right]+\left[\begin{array}{c}
\mathbf{A}_{4} \\
\mathbf{0}
\end{array}\right]\left[\mathbf{v}_{t}\right],
$$

which in obvious notation can be written as

$$
\mathbf{B}_{0} \mathbf{z}_{t}=\mathbf{B}_{1} \mathbf{z}_{t-1}+\mathbf{B}_{2} \mathrm{E}_{t} \mathbf{z}_{t+1}+\mathbf{B}_{3} \mathbf{v}_{t}
$$

By construction, the solution to equation (12) is unique, has the form

$$
\mathbf{z}_{t}=\mathbf{C}_{1} \mathbf{z}_{t-1}+\mathbf{C}_{2} \mathbf{v}_{t}
$$


and is equivalent to equations (9) and (10). ${ }^{4}$ We refer to this equilibrium as the optimal rational expectations equilibrium because equation (13) and equations (9) and (10) describe a rational expectations equilibrium in which monetary policy is set according to an optimal discretionary targeting rule.

\subsection{Implementability}

Evans and Honkapohja (2006) show that whether an optimal rational expectations equilibrium is learnable depends on the rule that the central bank uses to implement policy. In particular, if a state-contingent rule, like equation (10), which describes equilibrium outcomes for policy in the optimal rational expectations equilibrium, is used to conduct policy, then the optimal rational expectations equilibrium may not be learnable. In fact, the optimal rational expectations equilibrium can be implemented by a variety of instrument rules, with potentially different implications for determinacy and E-stability. But where the state-contingent rules that Evans and Honkapohja (2006) study are not consistent with learnability, they find that targeting rules, such as the ROE targeting rule (equation (6)) that we focus on in this paper, are. Because $\mathbf{Q}$ is positive definite, one way to implement this ROE targeting rule would be for the central bank to set policy to satisfy

$$
\mathbf{u}_{t}=-\mathbf{Q}^{-1} \mathbf{A}_{3}^{\prime} \mathbf{D}^{\prime-1} \mathbf{P} \mathbf{y}_{t}
$$

Although equation (14) leads to optimal outcomes under discretion it places important demands on the central bank. Specifically, it assumes that the central bank knows the parameters in the model, an assumption that we seek to relax. When the central bank is learning, the coefficient matrices in equation (14) will be governed by parameters that are estimated, rather than by the true parameters, but policy will still be conducted according to the ROE targeting rule.

Of course, equation (14) provides a vehicle for implementing the targeting rule associated with the time-consistent policy, not the optimal commitment policy. One reason to focus on discretion and time-consistent behavior is that the demands associated with the commitment policy are somewhat more taxing than those of the time-consistent policy. For instance, a central bank's credibility is likely to be sorely strained if it is continually revising its announced targeting rule as new parameter estimates are obtained. To implement an optimal commitment policy the central bank must commit to an announced targeting rule and to an

\footnotetext{
${ }^{4}$ To operationalize this procedure, one needs to find a fix-point in $\mathbf{P}, \mathbf{H}, \mathbf{G}, \mathbf{F}_{1}$, and $\mathbf{F}_{2}$. The details of how this fix-point can be obtained is discussed in Dennis (2007).
} 
announced updating rule for each of the parameters; such commitments might be hard to sustain.

\section{Real-time learning}

We study an environment in which both the central bank and the private sector must learn in real-time. Although all agents must learn, their information sets differ and their learning focuses on different aspects of the economy. The private sector, knowing its own behavioral parameters but needing to forecast future outcomes, must learn the economy's equilibrium law of motion, which takes the form of a VAR model, equation (13). The central bank, needing to set monetary policy, must learn the parameters in the economy's structural relationships. In the analysis that follows, we assume that the central bank knows $\delta, \theta$, and $\beta$ and needs only to estimate $\phi$ and $\lambda .^{5}$

With both private agents and the central bank learning, the first issue we address is whether the optimal rational expectations equilibrium is real-time learnable. For the optimal rational expectations equilibrium to be learnable, two conditions must hold. First, the central bank's real-time estimates of $\phi$ and $\lambda$ must converge to their true values, and second, the private sector's estimate of the economy's law of motion must converge to the equilibrium law of motion under full information and rational expectations. In contrast to the E-stability literature, we do not restrict our analysis to small perturbations about the optimal rational expectations equilibrium. Although local learnability is a necessary condition for real-time learnability, sampling variability associated with parameter estimation raises the possibility that the optimal rational expectations equilibrium may not be real-time learnable. Moreover, our analysis of real-time learning reveals the magnitude, or cost, of the policy errors that arise during the learning process and indicates the speed at which learning might be expected to occur.

\subsection{Private-sector learning}

With the private sector learning, the expectations in equation (12) are no longer formed rationally. Instead, expectations are formed according to the private sector's adaptive learning algorithm and denoted $\mathrm{E}_{t}^{*} \mathbf{z}_{t+1}$. To form expectations, private agents estimate a perceived law

\footnotetext{
${ }^{5}$ By focusing on the estimation of $\phi$ and $\lambda$ rather than of $\delta$ and $\theta$, we avoid a thorny issue in the central bank estimation problem: for values of $\delta$ and $\theta$ equal to zero, the instrument set would be invalid. Because the central bank cannot preclude that $\delta$ and $\theta$ may equal zero, it would be using a set of instruments that is invalid under possible population values of these parameters.
} 
of motion (PLM) that we assume mirrors the economy's rational expectations equilibrium, equation (13). More precisely, private agents recursively estimate $\mathbf{c}$ and $\mathbf{C}_{1}$ in the PLM

$$
\mathbf{z}_{t}=\mathbf{c}+\mathbf{C}_{1} \mathbf{z}_{t-1}+\mathbf{u}_{t}
$$

where a nonzero constant $\mathbf{c}$ has been added to allow for the fact that private agents do not know either the central bank's inflation target, $\bar{\pi}$, or the economy's (real) natural rate of interest, $\bar{r}$. Period $t$ estimates of $\mathbf{c}$ and $\mathbf{C}_{1}$ are obtained using either recursive least squares, a decreasing-gain learning algorithm, or the Kalman filter, a constant-gain learning algorithm, and are denoted $\widehat{\mathbf{c}}(t)$ and $\widehat{\mathbf{C}}_{1}(t)$. Then, private-sector expectations of next-period outcomes are given $b y^{6}$

$$
\mathrm{E}_{t}^{*} \mathbf{z}_{t+1}=\widehat{\mathbf{c}}(t)+\widehat{\mathbf{C}}_{1}(t) \mathbf{z}_{t}
$$

and their estimates of the inflation target, $\bar{\pi}$, and the natural rate of interest, $\bar{r}$, can be obtained as elements in $\mathrm{E}_{t}^{*} \overline{\mathbf{z}}$, according to

$$
\mathrm{E}_{t}^{*} \overline{\mathbf{z}}=\left[\mathbf{I}-\widehat{\mathbf{C}}_{1}(t)\right]^{-1} \widehat{\mathbf{c}}(t)
$$

\subsection{Central-bank learning}

At time $t$, the central bank estimates $\phi$ and $\lambda$ and implements the optimal discretionary policy using its estimates. Following Sargent (1999) and much of the literature on adaptive learning, the central bank is only boundedly rational because it neglects the effect of its current decision on future learning when setting policy (an issue examined in Wieland, 2000). Moreover, the central bank does not take into account the sampling variability of its parameter estimates, behaving instead as if the sample estimates were the population values. Finally, the central bank assumes that private-sector expectations are rational, so that a policy transmission channel operating through private-sector learning is closed down. These standard assumptions allow us to easily obtain and compare results under a variety of learning environments.

Given the simultaneity in the model, the central bank uses generalized instrumental variables (GIV) to estimate the model. Although ordinary least squares (OLS) and GIV are both biased estimators in finite samples, the GIV estimator, and not the OLS estimator, is asymptotically unbiased and consistent. Section 5.1 discusses the small sample properties

\footnotetext{
${ }^{6}$ Equation (16) shows that private sector forecasts are conditioned on current endogenous variables, which implies that current endogenous variables are in the private sector's information set. This timing assumption is adopted by Evans and Honkapohja (2006). An alternative assumption is that only $t-1$ endogenous variables enter the forecast. Evans and Honkapohja (2006) point out that the E-stability of the rational expectations equilibrium may depend on this timing assumption.
} 
of the central bank's estimator. The set of econometric instruments consists of $\pi_{t-1}$ if the central bank does not smooth interest rates, and $\pi_{t-1}, x_{t-1}$, and $i_{t-1}$ if the central bank does smooth interest rates. Because the forward-looking IS curve (equation (1)) and the Phillips curve (equation 2) contain two and three structural parameters, respectively, neither equation is fully identified in the absence of interest rate smoothing. As mentioned earlier, to overcome this identification problem, we assume that the weight $\nu$ in the policy objective function is always nonzero and focus on the estimation of $\phi$ and $\lambda$.

Recall that the structural relationships to be estimated are

$$
\begin{aligned}
\mathrm{E}_{t}\left[\left(x_{t}-\delta x_{t-1}-(1-\delta) x_{t+1}-\phi\left(i_{t}-\pi_{t+1}\right)\right) \mathbf{z}_{t}\right] & =0, \\
\mathrm{E}_{t}\left[\left(\pi_{t}-\theta \pi_{t-1}-(1-\theta) \beta \pi_{t+1}-\lambda x_{t}\right) \mathbf{z}_{t}\right] & =0 .
\end{aligned}
$$

From the definition of rational expectations, $\pi_{t+1}=\mathrm{E}_{t} \pi_{t+1}+\varepsilon_{t+1}^{\pi}$ and $x_{t+1}=\mathrm{E}_{t} x_{t+1}+\varepsilon_{t+1}^{x}$, where $\varepsilon_{t+1}^{\pi}$ and $\varepsilon_{t+1}^{x}$ are martingale difference sequences. Substituting realized values for expected values, define

$$
s_{t} \equiv x_{t}-\delta x_{t-1}-(1-\delta) x_{t+1}=\phi\left(i_{t}-\pi_{t+1}\right)+g_{t}-(1-\delta) \varepsilon_{t+1}^{x}-\phi \varepsilon_{t+1}^{\pi} .
$$

Similarly, once expected inflation is replaced with observed inflation, define

$$
p_{t} \equiv \pi_{t}-\theta \pi_{t-1}-(1-\theta) \beta \pi_{t+1}=\lambda x_{t}+u_{t}-(1-\theta) \beta \varepsilon_{t+1}^{\pi} .
$$

Define $r_{t} \equiv i_{t}-\pi_{t+1}$, and let $\mathbf{r}, \mathbf{s}, \mathbf{z}$, and $\mathbf{p}$ be vectors containing the time series on $r_{t}, s_{t}$, $z_{t}$, and $p_{t}$, respectively, and $\mathbf{r}_{-1}, \mathbf{s}_{-1}, \mathbf{z}_{-1}$, and $\mathbf{p}_{-1}$ represent the lag of these vectors. Then we obtain estimates of $\phi$ and $\lambda$ using

$$
\begin{aligned}
& \widehat{\phi}(t)=\left[\left(\mathbf{r}^{\prime} \mathbf{z}_{-1}\right)\left(\mathbf{z}_{-1}^{\prime} \mathbf{z}_{-1}\right)^{-1}\left(\mathbf{z}_{-1}^{\prime} \mathbf{r}\right)\right]^{-1}\left[\left(\mathbf{r}^{\prime} \mathbf{z}_{-1}\right)\left(\mathbf{z}_{-1}^{\prime} \mathbf{z}_{-1}\right)^{-1}\left(\mathbf{z}_{-1}^{\prime} \mathbf{s}\right)\right] \\
& \widehat{\lambda}(t)=\left[\left(\mathbf{x}^{\prime} \mathbf{z}_{-1}\right)\left(\mathbf{z}_{-1}^{\prime} \mathbf{z}_{-1}\right)^{-1}\left(\mathbf{z}_{-1}^{\prime} \mathbf{x}\right)\right]^{-1}\left[\left(\mathbf{x}^{\prime} \mathbf{z}_{-1}\right)\left(\mathbf{z}_{-1}^{\prime} \mathbf{z}_{-1}\right)^{-1}\left(\mathbf{z}_{-1}^{\prime} \mathbf{p}\right)\right] .
\end{aligned}
$$

Monetary policy at time $t+1$ is then conducted based on $\widehat{\phi}(t)$ and $\widehat{\lambda}(t)$.

\subsection{Temporary equilibrium}

Recall that the optimal rational expectations equilibrium can be obtained by solving the system

$$
\mathbf{B}_{0} \mathbf{z}_{t}=\mathbf{B}_{1} \mathbf{z}_{t-1}+\mathbf{B}_{2} \mathrm{E}_{t} \mathbf{z}_{t+1}+\mathbf{B}_{3} \mathbf{v}_{t}
$$


for its rational expectations equilibrium. If expectations were rational, then the equilibrium law of motion that satisfies equation (24) would describe the economy's actual law of motion (ALM). However, with both the central bank and private agents learning, the model differs from equation (24) for two reasons. First, the central bank's targeting rule places a restriction on the endogenous variables, a restriction that is based on its parameter estimates. Second, the expectations that enter the IS curve and the Phillips curve are formed according to the PLM, whose parameters are also estimated. As a consequence, the ALM is no longer the rational expectations solution of equation (24). Instead, combining central-bank learning and private-sector learning with the true model, the ALM is given by

$$
\mathbf{z}_{t+1}=\mathbf{c}^{*}(t)+\mathbf{C}_{1}^{*}(t) \mathbf{z}_{t}+\mathbf{C}_{2}^{*}(t) \mathbf{v}_{t+1}
$$

where

$$
\begin{aligned}
\mathbf{c}^{*}(t) & =\left[\widehat{\mathbf{B}}_{0}(t)-\mathbf{B}_{2} \widehat{\mathbf{C}}_{1}(t)\right]^{-1} \mathbf{B}_{2} \widehat{\mathbf{c}}(t), \\
\mathbf{C}_{1}^{*}(t) & =\left[\widehat{\mathbf{B}}_{0}(t)-\mathbf{B}_{2} \widehat{\mathbf{C}}_{1}(t)\right]^{-1} \mathbf{B}_{1}, \\
\mathbf{C}_{2}^{*}(t) & =\left[\widehat{\mathbf{B}}_{0}(t)-\mathbf{B}_{2} \widehat{\mathbf{C}}_{1}(t)\right]^{-1} \mathbf{B}_{3} .
\end{aligned}
$$

Equation (25) governs how $\mathbf{z}_{t+1}$ is determined, given $\mathbf{z}_{t}$ and $\mathbf{v}_{t+1}$, and describes a temporary, period $t$, equilibrium of the economy. Our study of real-time learnability essentially examines the behavior of this temporary equilibrium as additional information becomes available, focusing on whether it converges to the optimal rational expectations equilibrium.

With the central bank and the private sector both learning, real-time learnability of the optimal rational expectations equilibrium implies that $\phi$ and $\lambda$ are real-time learnable by the central bank and that $\mathbf{c}$ and $\mathbf{C}_{1}$ are real-time learnable by the private sector. If $\phi$ and $\lambda$ are real-time learnable by the central bank, then this implies that $\widehat{\mathbf{B}}_{0}(t) \rightarrow \mathbf{B}_{0}$ as $t$ tends to $\infty$. But, at $\widehat{\mathbf{B}}_{0}(t)=\mathbf{B}_{0}$, as $t$ tends to $\infty, \mathbf{C}_{1}^{*}(t)$ is known to converge to the solution, $\mathbf{C}_{1}^{*}$, for which the eigenvalues of $\left(\mathbf{B}_{0}-\mathbf{B}_{2} \mathbf{C}_{1}^{*}\right)^{-1} \mathbf{B}_{1}$ and $\left[\left(\mathbf{B}_{0}-\mathbf{B}_{2} \mathbf{C}_{1}^{*}\right)^{-1} \mathbf{B}_{1}\right] \otimes\left[\left(\mathbf{B}_{0}-\mathbf{B}_{2} \mathbf{C}_{1}^{*}\right)^{-1} \mathbf{B}_{1}\right]$ all have real parts less than one (see Evans and Honkapohja, 2001). If the eigenvalues of $\mathbf{C}_{1}^{*}$ are bounded by 1 in modulus, then this solution, $\mathbf{C}_{1}^{*}$, coincides with $\mathbf{C}_{1}$ in the optimal rational expectations equilibrium. More generally, we can imagine cases where $\widehat{\mathbf{B}}_{0}(t) \rightarrow \overline{\mathbf{B}}^{0} \neq \mathbf{B}_{0}$, where $\mathbf{C}_{1}^{*}(t) \rightarrow \mathbf{C}_{1}^{*} \neq \mathbf{C}_{1}$, and/or where neither $\widehat{\mathbf{B}}_{0}(t)$ nor $\mathbf{C}_{1}^{*}(t)$ converge at all, situations where the optimal rational expectations equilibrium is not real-time learnable by either the central bank or the private sector. 
Situations where either only the central bank is learning or only the private sector is learning also give rise to temporary equilibria. When only private agents are learning, the central bank's targeting rule is based on the true structural parameters and the Euler condition implementing the optimal rational expectations equilibrium policy is contained in $\mathbf{B}_{0}$. Then, the temporary equilibrium is given by equations (25) through (28) after setting $\widehat{\mathbf{B}}_{0}(t)=\mathbf{B}_{0}$, $\forall t$. Similarly, when only the central bank is learning, private-sector expectations of $\mathbf{z}_{t+1}$ $\left(\mathrm{E}_{t} \mathbf{z}_{t+1}\right)$ are rational, conditional on the central bank's targeting rule, which is a function of $\widehat{\phi}(t)$ and $\widehat{\lambda}(t)$. In this case, the targeting rule is contained in the matrix $\widehat{\mathbf{B}}_{0}(t)$. Because they are formed assuming $\widehat{\phi}(t)$ and $\widehat{\lambda}(t)$ are fixed for all $t$, private-sector expectations, while obtained as the solution to a fix-point problem, are actually bounded rational. Then, the temporary equilibrium is given by equations (25) through (28) after imposing $\widehat{\mathbf{C}}_{1}(t)=\mathbf{C}_{1}^{*}(t)$, and solving for the fix-point, $\mathbf{C}_{1}^{*}(t)$, that satisfies equation $(27)$.

\subsection{Existence of a unique stable rational expectations equilibrium}

The true model has a unique stable rational expectations equilibrium. However, in the realtime learning environment the central bank policy depends on $\widehat{\phi}(t)$ and $\widehat{\lambda}(t)$ and volatility of the GIV estimator opens the door to the possibility that parameter estimates may occur that imply a policy for which there is no unique, stable rational expectations equilibrium. The appendix discusses the existence of the rational expectations equilibrium and shows how initial sample size and policymaker preferences affect the probability of obtaining GIV estimates implying the nonexistence of a unique, stable rational expectations equilibrium. In the realtime learning environment, we restrict the estimates $\widehat{\phi}(t)$ and $\widehat{\lambda}(t)$ to belong to the parameter set for which a unique, stable rational expectations equilibrium exists. Specifically, if a unique stable rational expectations equilibrium does not exist for the estimates obtained, then we assume the central bank retains its period $t-1$ estimates. $^{7}$ Although this assumption is only necessary in situations where only the central bank is learning, for consistency it is imposed on all numerical simulations.

\footnotetext{
${ }^{7}$ Related adjustments are made by Marcet and Sargent (1989) and Orphanides and Williams (2006). To prevent the private sector's learning algorithm from generating explosive expectations, these studies examine the eigenvalues of the estimated PLM and assume that private agents adopt their estimated PLM, which is in the form of a $\operatorname{VAR}(1)$, only if the eigenvalues are all less than 1 in modulus.
} 


\section{Real-time learnability results}

Having outlined how the economy evolves when both the central bank and the private sector are learning and having discussed what is meant by real-time learnability of the optimal rational expectations equilibrium, we now study the impact of real-time learning in the model. Before studying learning dynamics, we first examine real-time learnability of the optimal rational expectations equilibrium by simulating the learning environment, given an initial sample of 200 observations. These initial observations were generated using the model in equations (1) and (2) under the assumption that monetary policy was set according to the rational expectations equilibrium optimal discretionary rule. ${ }^{8}$ The central bank estimated $\phi$ and $\lambda$ using recursive GIV, while private agents estimated their PLM using recursive OLS. Simulations allowing learning to occur for as many as 200,000 periods confirmed that the real-time parameter estimates converged to their true values. Therefore, with real-time learning by private agents and the central bank, and with real-time policymaking, the economy converged to a fix-point, and that fix-point was the optimal rational expectations equilibrium. Similarly, learnability of the optimal rational expectations equilibrium also occurred when only the central bank was learning and when only the private sector was learning.

Of course, real-time learnability of the optimal rational expectations equilibrium does not convey any information about the cost of learning or about the speed at which learning occurs. To investigate these issues, we simulate the learning environment for 2,000 periods beyond the initial 200 observations and construct distributions for each parameter by repeating this learning exercise 1,000 times. To assess the cost of learning, for each period we compute the loss function (3) evaluated using the temporary equilibrium law of motion described by equation (25). Define this loss measure to be

$$
L_{t}^{*}=L\left[\mathbf{c}^{*}(t), \mathbf{C}_{1}^{*}(t), \mathbf{C}_{2}^{*}(t)\right]
$$

$L_{t}^{*}$ represents the loss attained by the policymaker when the optimal policy is computed using its time $t$ parameter estimates and when the private sector computes expectations using its time $t$ PLM. Because real-time learnability implies that the ALM converges to the optimal rational

\footnotetext{
${ }^{8}$ To be explicit, for our benchmark policy regime, the data generating process for the 200 initial observations to 3 decimal places is$$
\left[\begin{array}{c}
\pi_{t+1} \\
x_{t+1} \\
i_{t+1}
\end{array}\right]=\left[\begin{array}{ccc}
0.318 & 0.119 & -0.104 \\
-0.084 & 0.255 & -0.147 \\
0.156 & 0.425 & 0.139
\end{array}\right]\left[\begin{array}{c}
\pi_{t} \\
x_{t} \\
i_{t}
\end{array}\right]+\left[\begin{array}{cc}
1.060 & 0.237 \\
-0.282 & 0.511 \\
0.521 & 0.850
\end{array}\right]\left[\begin{array}{l}
u_{t+1} \\
g_{t+1}
\end{array}\right] .
$$ 
expectations equilibrium, as $t \uparrow \infty, L_{t}^{*}$ converges to the rational expectations equilibrium level of loss, $L$. If the central bank were to stop learning and to use its current estimates of $\phi$ and $\lambda$ to set policy in the future, then the distance between $L_{t}^{*}$ and $L$ provides a measure of the cost to the central bank of having a finite sample with which to learn. ${ }^{9}$ This measure of the cost of learning implies we are looking at the loss arising from the optimal rational expectations equilibrium not being learned by time $t$. Intuitively, if a short sample can deliver a loss, $L_{t}^{*}$, close to $L$, regardless of how fast agents learn the true model, then the cost to deviations from the optimal equilibrium are small and learning has only minor implications for optimal policymaking.
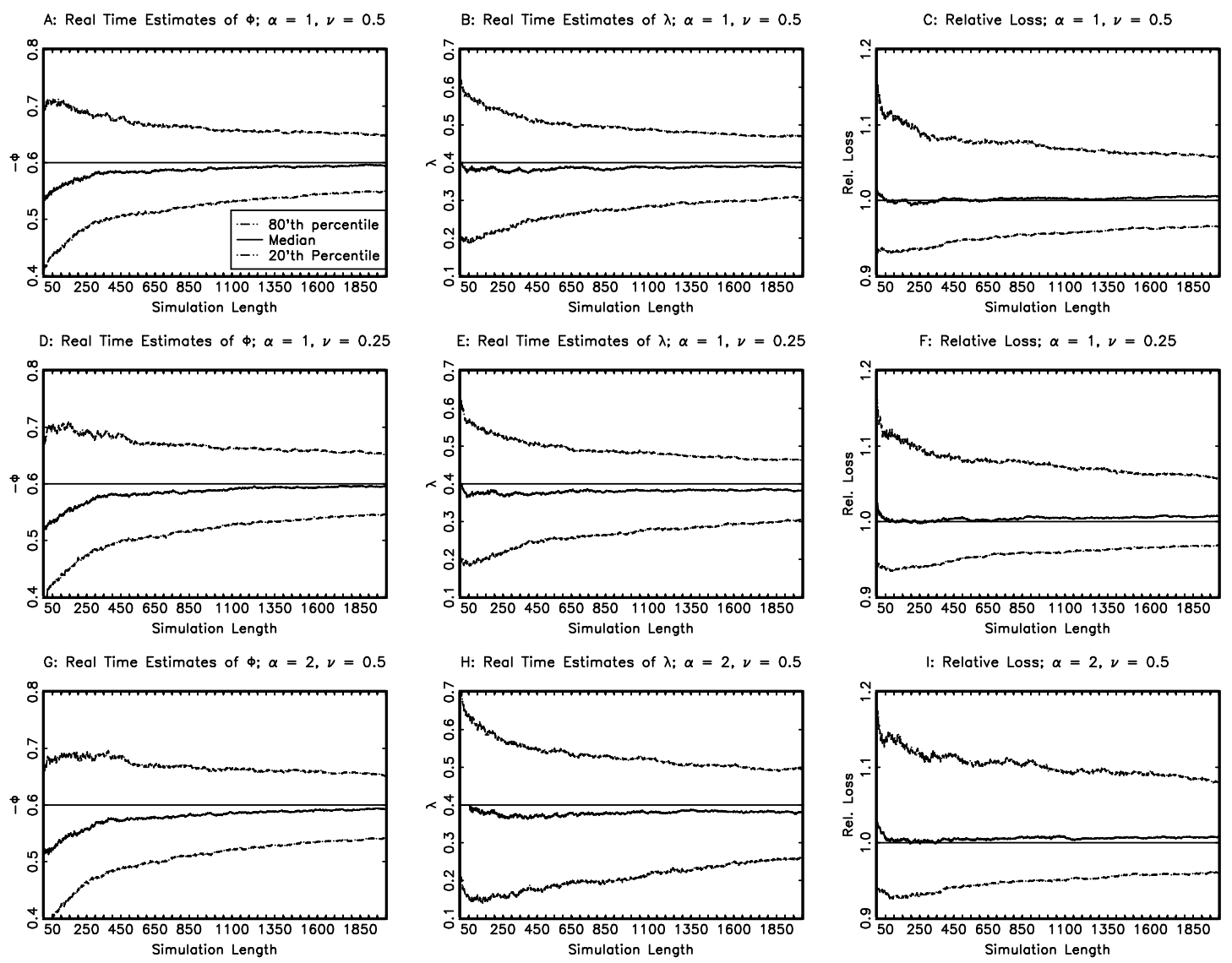

Fig. 1: Real-time estimation with central-bank and private-sector learning

Figure 1 shows the median, and the 20th and 80th percentiles of the simulated distributions of $\phi(t)$ and $\lambda(t)$ for three policy regimes. Also shown are the corresponding statistics for $\frac{L_{t}^{*}}{L}$,

\footnotetext{
${ }^{9}$ An advantage of this measure is that at each time $t$ it depends only on the past data. An alternative measure of the cost of learning is the total discounted loss averaged across simulations. This is a measure of the cumulative loss of converging to the optimal rational expectations equilibrium, as evaluated at time $t$. While clearly related to $W_{t}^{*}$, it depends on the whole future sequence of ALM.
} 
the value of the loss function at each time $t$ relative to the loss the policymaker would obtain in the optimal rational expectations equilibrium. Because lower values of loss function are better, relative loss values that are greater than one indicate that learning adversely affects loss. To facilitate comparison, the same shocks are applied for each policy regime. The simulations assume that 200 initial observations (50 years of data) generated from the true model are available, from which initial estimates are obtained, and that both the central bank and the private sector are learning, using recursive GIV and recursive OLS, respectively. As noted in Section 3.2, due to simultaneity, $\phi$ and $\lambda$ are estimated using GIV and are each subject to a finite-sample bias; this finite-sample bias is reflected in Figure 1

Although the central bank can eventually learn the structural parameters, Figure 1 shows that learning occurs slowly for each policy regime. Notably, sampling variation in $\widehat{\phi}(t)$ and $\widehat{\lambda}(t)$ is considerable, especially when the sample size is small, and decreases only gradually as the sample size increases. Where estimates of $\phi$, the intertemporal elasticity of substitution, appear to be reasonably unaffected by the choice of monetary policy regime, they are biased downward, which is particularly evident when the sample size is small. As expected, as the sample size increases, the bias in $\widehat{\phi}(t)$ disappears. Turning to the real-time estimates of the slope coefficient in the Phillips curve, $\lambda$, we find that when the sample size is small the estimates are biased downward, implying an upward bias in the estimate of price stickiness. In addition, the estimates of $\lambda$ are affected materially by the policy regime. Specifically, when the weight on interest rate smoothing is small relative to the weight on output stabilization, the sampling variation in the estimates of $\lambda$ increases.

The fact that the central bank learns slowly does not necessarily imply that the cost to learning is large. A striking feature of Figure 1 is that learning is not always detrimental. Relative to the optimal rational expectations equilibrium, learning improves outcomes roughly 50 percent of the time for all three policy regimes. Although this result may seem surprising at first, it has a clear intuition. Discretionary policies, while time-consistent, are not optimal, and, as a consequence, there exist policies that outperform the optimal discretionary rule. The extent to which discretionary policies are suboptimal depends on the magnitude of the stabilization bias, a term describing the fact that in New Keynesian models discretionary policies understabilize inflation and overstabilize the output gap relative to fully optimal policies. When the central bank is learning, its estimates of $\lambda$ and $\phi$ can serve to counteract the magnitude of this stabilization bias. In particular, the central bank will tend to intervene more aggressively, raising the volatility of the output gap and lowering the volatility of inflation, if 
it overestimates the degree of price rigidity (i.e., it underestimates $\lambda$ ) or underestimates the elasticity of intertemporal substitution (i.e., it underestimates $\phi$ ).

To see how these mechanisms work, consider the price rigidity case. If the central bank overestimates the degree of price rigidity, then it underestimates the slope of the Phillips curve. Consequently, the central bank believes that it must induce a larger change in the output gap in order to change inflation by a given amount. By basing its policy on this perception, the central bank's policy raises the volatility of the output gap and, because inflation is actually more sensitive to the output gap than the central bank believes, these movements in the output gap damp the volatility of inflation more than the central bank anticipates.

Furthermore, private-agent learning, by changing the persistence of inflation and the output gap, can potentially help to stabilize the economy. As we show in detail in Section 5, together or individually, these factors can lead to outcomes under learning that are better than under full information. However, as more data become available and the parameter estimates become more precise, the likelihood of obtaining a loss that is close to the level for optimal rational expectations equilibrium gradually increases.

\subsection{Learning and interest rate smoothing}

To assess the role of interest rate smoothing in the objective function, in Table 1 we compare the baseline policy regime with a regime in which the weight on interest rate smoothing is 0.05. Table 1 reveals that when the weight on interest rate smoothing is small, the relative loss distribution is skewed toward larger loss and learning has a larger probability of being costly. This result can be traced to the fact that with a small weight on the interest rate objective the parameter $\lambda$, the slope of the Phillips curve, is difficult to estimate precisely. By smoothing interest rates, the central bank allows demand shocks to affect the economy and this additional source of variation allows $\lambda$ to be estimated with greater precision. The bias

and precision of $\widehat{\lambda}(t)$ are important for monetary policy because $\lambda$ is critical for determining the rate at which the central bank can trade off a higher output variance for a lower inflation variance. 


\begin{tabular}{|c|c|c|c|c|c|c|c|c|c|c|c|c|}
\hline & \multicolumn{6}{|c|}{$\alpha=1, \nu=0.5$} & \multicolumn{6}{|c|}{$\alpha=1, \nu=0.05$} \\
\hline & \multirow{2}{*}{\multicolumn{3}{|c|}{$\begin{array}{l}50 \text { periods } \\
\text { Percentile }\end{array}$}} & \multirow{2}{*}{\multicolumn{3}{|c|}{$\begin{array}{c}200 \text { periods } \\
\text { Percentile }\end{array}$}} & \multirow{2}{*}{\multicolumn{3}{|c|}{$\begin{array}{l}50 \text { periods } \\
\text { Percentile }\end{array}$}} & \multirow{2}{*}{\multicolumn{3}{|c|}{$\begin{array}{c}200 \text { periods } \\
\text { Percentile }\end{array}$}} \\
\hline & & & & & & & & & & & & \\
\hline & 20 & 50 & 80 & 20 & 50 & 80 & 20 & 50 & 80 & 20 & 50 & 80 \\
\hline$\widehat{\phi}(t)$ & 0.44 & 0.55 & 0.70 & 0.48 & 0.57 & 0.69 & 0.32 & 0.44 & 0.60 & 0.39 & 0.49 & 0.65 \\
\hline$\widehat{\lambda}(t)$ & 0.19 & 0.38 & 0.58 & 0.21 & 0.39 & 0.54 & 0.17 & 0.36 & 0.56 & 0.17 & 0.36 & 0.52 \\
\hline$\widehat{\bar{\pi}}(t)$ & -0.04 & 0.00 & 0.04 & -0.05 & 0.00 & 0.05 & -0.04 & 0.00 & 0.04 & -0.05 & 0.00 & 0.04 \\
\hline$\widehat{\bar{r}}(t)$ & -0.03 & 0.00 & 0.04 & -0.03 & 0.00 & 0.03 & -0.04 & 0.00 & 0.04 & -0.04 & 0.00 & 0.03 \\
\hline$\frac{L_{t}^{*}}{L}$ & 0.93 & 1.00 & 1.11 & 0.94 & 0.99 & 1.10 & 0.92 & 1.00 & 1.14 & 0.94 & 1.00 & 1.16 \\
\hline
\end{tabular}

Interestingly, were the policy regime parameters choice variables for the central bank, then the results in Table 1 might suggest a potential role for optimal experimentation by the central bank, along the lines of Wieland (2000). Specifically, even if the weight on interest rate smoothing in society's loss function were small, to help it learn the economy's structure the central bank might choose initially to overweight interest rate smoothing. With a higher weight on interest rate smoothing, the central bank responds less to shocks and inflation and the output gap can become more volatile, which can assist learning.

\subsection{Decreasing-gain versus constant-gain learning}

Table 2 reports what happens if private agents learn using the Kalman filter, with the gain set to 0.02 rather than using recursive least squares. Again, there are 200 initial observations and the central bank learns using recursive GIV. Table 2 reveals that the central bank's estimates converge to the true parameters, implying that the optimal policy is learnable, even though private agents never learn the law of motion for the optimal rational expectations equilibrium. Table 2 also shows that, in an environment where the true model is stationary, constant-gain learning is largely equivalent to least-squares learning. ${ }^{10}$

\footnotetext{
${ }^{10}$ By way of contrast, in Section 6 we show that constant-gain learning can lead to a substantial increase in loss for some nonstationary learning environments.
} 


\begin{tabular}{|c|c|c|c|c|c|c|c|c|c|c|c|c|}
\hline & \multicolumn{6}{|c|}{ Decreasing-gain learning } & \multicolumn{6}{|c|}{ Constant-gain learning } \\
\hline & \multirow{2}{*}{\multicolumn{3}{|c|}{$\begin{array}{c}50 \text { periods } \\
\text { Percentile }\end{array}$}} & \multirow{2}{*}{\multicolumn{3}{|c|}{$\begin{array}{c}200 \text { periods } \\
\text { Percentile }\end{array}$}} & \multirow{2}{*}{\multicolumn{3}{|c|}{$\begin{array}{l}50 \text { periods } \\
\text { Percentile }\end{array}$}} & \multirow{2}{*}{\multicolumn{3}{|c|}{$\begin{array}{c}200 \text { periods } \\
\text { Percentile }\end{array}$}} \\
\hline & & & & & & & & & & & & \\
\hline & 20 & 50 & 80 & 20 & 50 & 80 & 20 & 50 & 80 & 20 & 50 & 80 \\
\hline$\widehat{\phi}(t)$ & 0.44 & 0.55 & 0.70 & 0.48 & 0.57 & 0.69 & 0.44 & 0.55 & 0.70 & 0.47 & 0.56 & 0.68 \\
\hline$\widehat{\lambda}(t)$ & 0.19 & 0.38 & 0.58 & 0.21 & 0.39 & 0.54 & 0.19 & 0.38 & 0.57 & 0.22 & 0.39 & 0.54 \\
\hline$\widehat{\bar{\pi}}(t)$ & -0.04 & 0.00 & 0.04 & -0.05 & 0.00 & 0.05 & -0.09 & 0.00 & 0.08 & -0.16 & 0.01 & 0.14 \\
\hline$\widehat{\bar{r}}(t)$ & -0.03 & 0.00 & 0.04 & -0.03 & 0.00 & 0.03 & -0.06 & 0.00 & 0.06 & -0.07 & 0.00 & 0.07 \\
\hline$\frac{L_{t}^{*}}{L}$ & 0.93 & 1.00 & 1.11 & 0.94 & 0.99 & 1.10 & 0.90 & 1.00 & 1.17 & 0.90 & 1.03 & 1.17 \\
\hline
\end{tabular}

\section{Understanding the impact of learning}

What accounts for the slow speed with which the central bank learns the true parameters and the impact of learning on relative loss? The results in the previous section stem from the interaction among three different factors: the central bank's learning algorithm, the privatesector's learning algorithm, and real-time policymaking, with each factor affecting the ALM each period. This section examines how private-sector and central-bank learning behavior affects the real-time learning results.

\subsection{Estimator behavior and the speed of learning}

The speed with which the structural parameters are learned depends on the properties of the GIV estimator used by the central bank and on how the ALM changes each period. The impact of real-time learning and policymaking can be gauged by shutting off these two channels and focusing on parameter estimation in the absence of learning. This experiment accomplishes two goals. First, it establishes the level of parameter variation that can be expected independent of learning. Second, it allows us to identify the properties and characteristics of the model and of real-time estimation that are unrelated to feedback into model dynamics from learning.

Assume, then, that private agents and the central bank each know the economy's correct structure and the true values for the structural parameters. Further assume that monetary policy is set according to an optimal discretionary rule and that all agents form rational expectations. Data generated from this environment are then collected by an econometrician who is assumed to know the model's structure but not its complete parameterization. Then, to examine the properties of the GIV estimator in the context of this model, we perform a simple Monte Carlo exercise. As earlier, we begin with a sample of 200 observations generated using 
the true model with rational expectations and simulate forward for 2,000 periods. Repeating this exercise 1,000 times, we construct simulated distributions for each parameter.

Figure 2 shows the 20th, the 50th, and the 80th percentiles of the simulated distributions for $\lambda$ and $\phi$ under three policy regimes. For comparison across policy regimes and with the real-time learning simulations in Figure 1, we apply the same shocks.
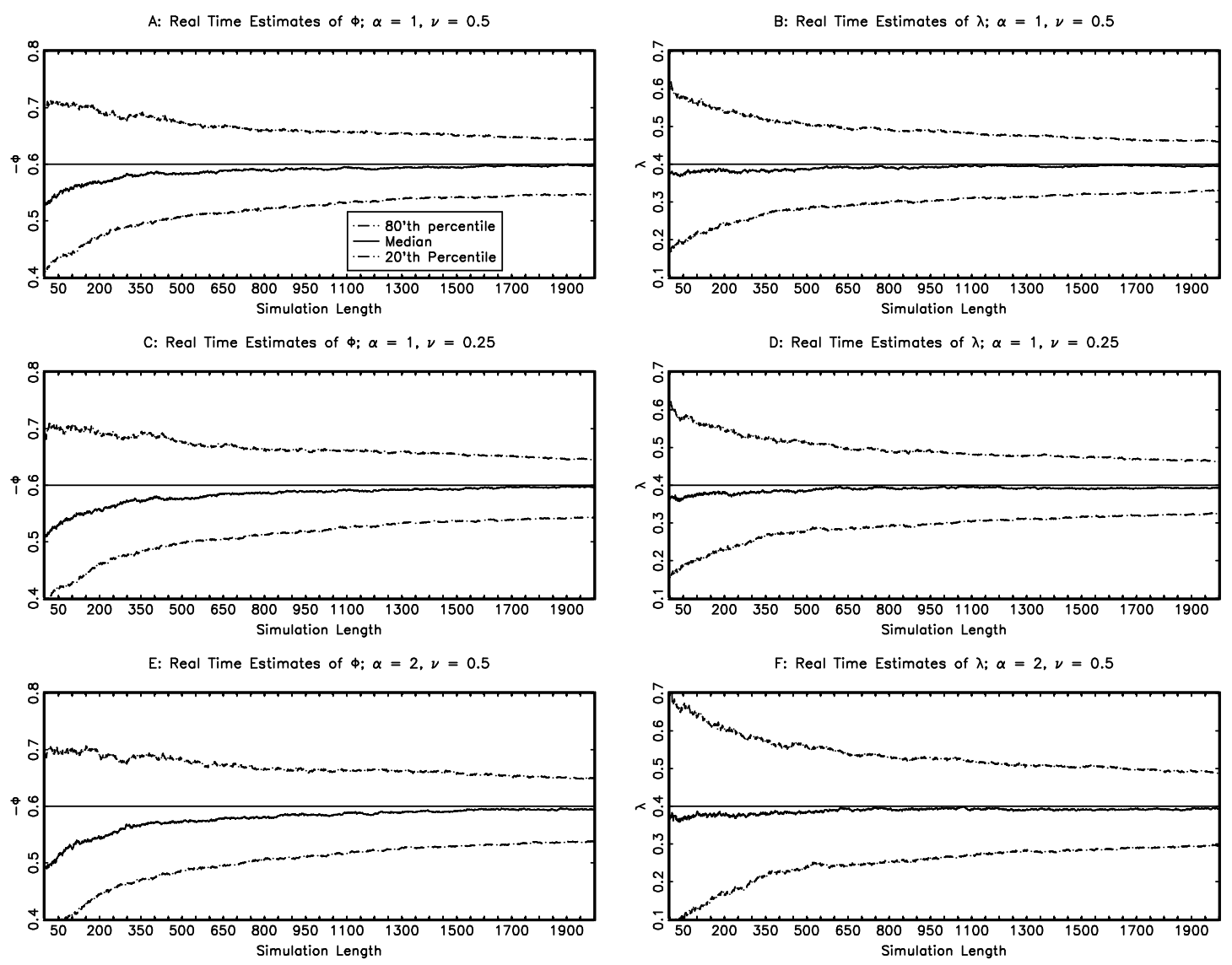

Fig. 2: Real-time estimation without learning

Several characteristics of the estimation exercise that have important implications for learning are illustrated in Figure 2. First, there is considerable sampling variation in $\widehat{\phi}(t)$ and $\widehat{\lambda}(t)$, especially when the sample size is small. This sampling variability is an issue for realtime learning because, if the central bank were to design a policy that employed parameter estimates from the tails of the distributions, then that policy could easily generate a system that has no rational expectations equilibrium.

Second, because the sampling variation indicates how quickly the estimator converges to the true value, it also indicates the speed at which model parameters can be ideally learned. Comparing the parameter estimates between Figures 1 and 2, it is clear that the estimated 
distributions and the speed of convergence are generally very similar under each policy regime. This result implies that when policy is set in real-time there is relatively little feedback from the estimated policy to subsequent parameter estimates, and the change in the ALM originating from the private-sector model updating has little impact on the speed of learning. The bulk of the variation in the real-time parameter estimates is due to sampling variation and the properties of the GIV estimator. In essence, although learning the true parameters may be difficult, the central bank's learning problem is not materially compounded by its past policy decisions, or by private-sector learning behavior. Figure 2 also shows that the higher volatility in $\hat{\lambda}(t)$ observed in Figure 1, for the case where the central bank assigns only a trivial weight to interest rate smoothing, can be traced fully to poorer performance of the GIV estimator under this policy regime.

\subsection{Learning and relative loss}

A key result of Section 4 is that learning can improve relative loss. Two mechanisms explain this improvement. First, the central bank's estimated parameters can produce optimization constraints that distort the central bank's policy in the direction of the optimal commitment policy, a policy that is infeasible, because it is not time-consistent, when the central bank is constrained by the true structural relationships. This mechanism is at work regardless of private-sector learning. Second, conditional on the policy chosen by the central bank, the economy's actual law of motion differs from the rational expectations equilibrium when the private sector is learning. Private-sector expectations converge only asymptotically to rational expectations. While learning continues, the actual law of motion is not given by the solution to a fixed-point problem, and the resulting dynamics of the economy can generate a lower loss than under rational expectations. 

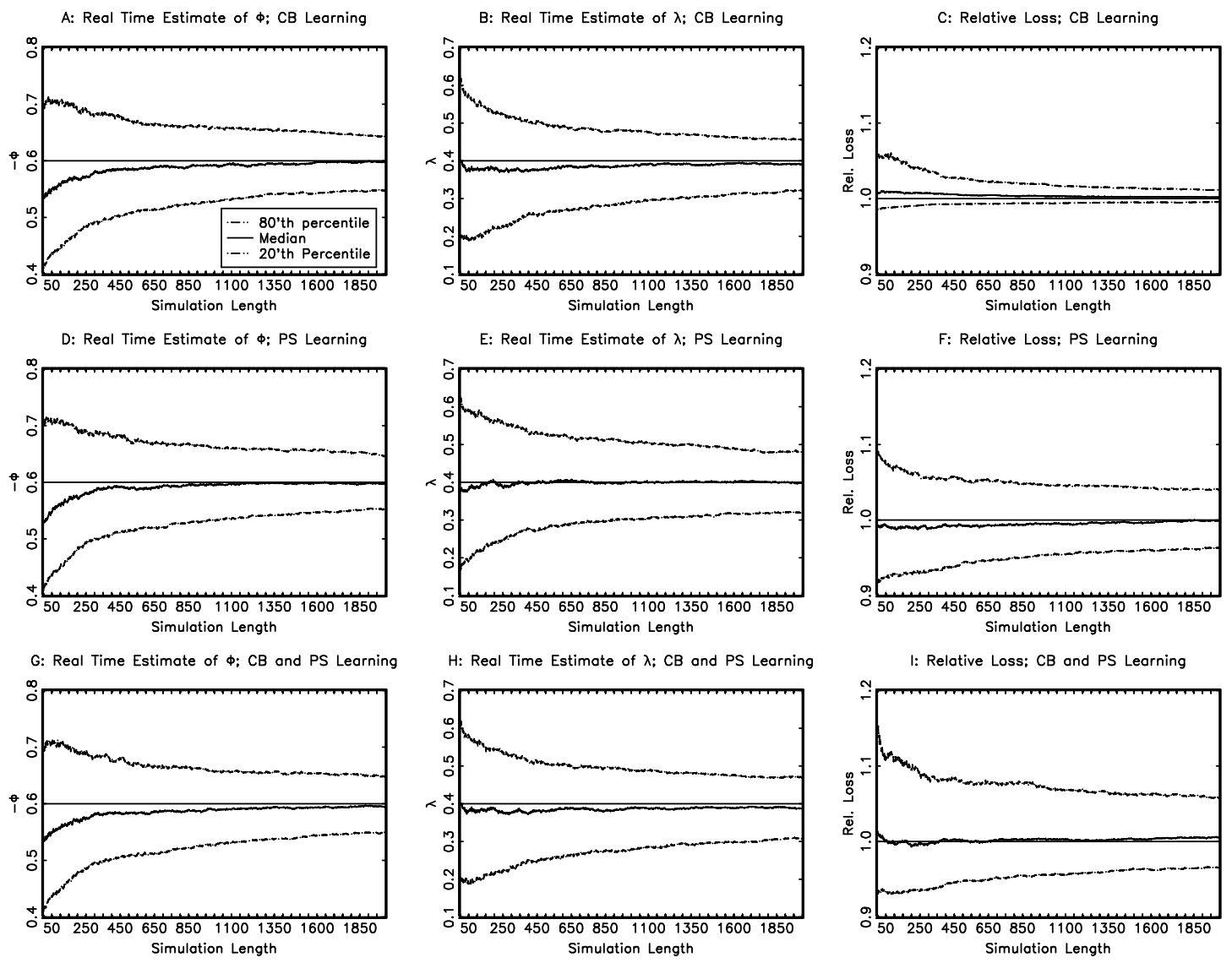

Fig. 3: The effects of learning on parameter estimation and relative loss

To investigate how improvements in relative loss arise, Figure 3 shows how private-sector learning and central-bank learning affect parameter estimation and relative loss under the benchmark policy regime. When only the central bank is learning (panels $\mathrm{A}-\mathrm{C}$ ) the median relative loss is greater than one, illustrating that, in and of itself, central-bank learning is costly most of the time. However, improved outcomes do occur with non-negligible probability. With private-sector learning shut off, this variation in loss relative to the optimal rational expectations equilibrium arises from the variation associated with the central bank's estimates of the structural parameters. From the central bank's perspective, it is implementing the optimal discretionary policy given its parameter estimates, but these parameter estimates twist, or distort, the constraints in the central bank's optimization problem to the extent that they differ from the true values. Depending on the particular set of estimates obtained, the discretionary central bank may perceive a trade-off between output and inflation that causes it to implement a policy that better stabilizes inflation (at the expense of stabilizing output), mitigating the magnitude of the discretionary stabilization bias and thereby achieving 
a value for the loss function superior to that obtained by the optimal discretionary policy when expectations are rational. ${ }^{11}$ In such a situation, as the central bank accumulates information about the economy, relative loss can actually increase.

In contrast, when only the private sector is learning (panels D - F) the median relative loss is less than one. That is, where central-bank learning generally leads to worse outcomes and to a rise in relative loss, private-sector learning often produces better outcomes and a decline in relative loss. This result stems from the fact that the private sector forms expectations using a learning algorithm, recursive OLS, that understates (downward-biases) the persistence in the law of motion in finite samples. ${ }^{12}$ As a consequence, the private sector's estimates of future inflation are biased toward and more tightly anchored on the central bank's inflation target (the unconditional mean of inflation), making the central bank's stabilization job easier. Put differently, if the central bank could convince the private sector that future inflation would be lower than what its policy implies, then policy loss would be lowered. Under rational expectations and discretionary policymaking, this cannot be an equilibrium because the central bank cannot make credible commitments. However, when private agents are learning, the central bank does not need credible commitments to alter private-sector beliefs about future inflation: private sector inflation expectations become better anchored simply as a consequence of the private-sector's learning algorithm. Note, however, that the improvement in loss does not originate from the central bank purposefully trying to shape private-sector expectations, or even from it trying to exploit how the private sector forms expectations; the anchoring of expectations arising from the private sector's learning algorithm delivers the result. ${ }^{13}$

\footnotetext{
${ }^{11}$ Nevertheless, when the central bank is the only agent that is learning, the loss under discretionary policymaking and learning cannot outperform the loss under commitment and rational expectations.

${ }^{12}$ This bias is no different from the standard coefficient bias associated with OLS in models containing lagged-dependent variables (Orcutt and Winokur, 1969). As is well-known, despite this finite-sample bias, OLS remains consistent, justifying its application in such cases.

${ }^{13}$ In the univariate case, the effect of this coefficient bias on loss is easy to see. Consider the univariate process

$$
z_{t}=b z_{t-1}+c \mathrm{E}_{t}^{*} z_{t+1}+v_{t}
$$

$\{b, c\} \in(0,1),|b+c|<1$, in which private-sector expectations are formed according to

$$
\mathrm{E}_{t}^{*} z_{t+1}=h z_{t}
$$

where $h$ is estimated. With this learning algorithm, the actual law of motion is

$$
z_{t}=(1-c h)^{-1} b z_{t-1}+(1-c h)^{-1} v_{t} .
$$

If $h$ is biased downward, then $(1-c h)^{-1} b$ is also biased downward. If the loss function is quadratic in $z_{t}$, then this downward bias in the actual law of motion leads to lower loss. The result in the text is a multivariate extension of this univariate result.
} 
When both the private sector and the central bank are learning (panels $\mathrm{G}-\mathrm{I}$ ), the increase in loss associated with central-bank learning is largely offset by the decline in loss associated with private-sector learning, bringing median relative loss back toward one.

\section{Private-sector learning and structural change}

The importance of private-sector learning for the central bank's policy loss is illustrated clearly in Figure 3. In this section we explore the importance of private-sector learning and its connection to central bank transparency, considering the learning dynamics and the effect on policy loss that arises when private agents must learn about structural breaks in three important parameters. The first structural break is a change to the real natural rate of interest, which in our model equals the steady-state real interest rate. The second structural break is a change to the central bank's inflation target. The final experiment we run is a structural break in the relative weight the central bank places on output stabilization relative to inflation stabilization. In each of these experiments the central bank employs the rational expectations equilibrium optimal policy while private agents are learning. Although private agents are unaware that a structural break has occurred, they are alert to the possibility of structural change and forecast the future output gap and future inflation using the Kalman filter with the gain set to 0.02 .

Because private agents learn using the Kalman filter, they are never certain of the true values of the inflation target or the natural rate of interest, even in a world without structural change. This uncertainty about the inflation target and the natural rate implies that as the sample size increases the loss function evaluated conditional on information at time $t$ does not converge in probability to the loss function evaluated under full information. Instead, the private sector's uncertainty about these parameters leads to the evaluated loss converging to a distribution that is centered on a value higher than the policy loss under full information. Intuition for this result can be gained by noticing that with equation (14) written as $\mathbf{u}_{t}=$ $-\mathbf{F} \mathbf{y}_{t}$, the loss function under learning (equation (29)) can be expressed in the form

$$
L_{t}^{*}-L=\frac{\beta}{1-\beta}\left[\left(\mathbf{c}^{*}(t)-\mathbf{c}\right)^{\prime} \widetilde{\mathbf{P}}\left(\mathbf{c}^{*}(t)-\mathbf{c}\right)+\operatorname{tr}\left[\left(\mathbf{C}_{2}^{*}(t)-\mathbf{C}_{2}\right)^{\prime} \widetilde{\mathbf{P}}\left(\mathbf{C}_{2}^{*}(t)-\mathbf{C}_{2}\right) \mathbf{\Omega}\right]\right],
$$

where

$$
\widetilde{\mathbf{P}}=\mathbf{W}+\mathbf{F}^{\prime} \mathbf{Q F}+\beta\left(\mathbf{C}_{1}^{*}(t)-\mathbf{C}_{1}\right)^{\prime} \widetilde{\mathbf{P}}\left(\mathbf{C}_{1}^{*}(t)-\mathbf{C}_{1}\right)
$$

and $L_{t}^{*}$ is the expected loss in equation (5) conditional on the time- $t$ policy and private-sector expectations. Under decreasing-gain learning, $\left\{\mathbf{c}^{*}(t), \mathbf{C}_{1}^{*}(t), \mathbf{C}_{2}^{*}(t)\right\} \longrightarrow\left\{\mathbf{c}, \mathbf{C}_{1}, \mathbf{C}_{2}\right\}$ and 
$L_{t}^{*} \longrightarrow L$ in the limit as $t \uparrow \infty$. However, under constant-gain learning, $L_{t}^{*}$ converges to a distribution, the average value of the quadratic terms in equation (30) is always positive, and, as a consequence, the average value of $L_{t}^{*}$ converges to $L^{*}>L$ even in the limit as $t \uparrow \infty$. For this reason, in this section only, the relative loss measures that we report are not taken with respect to the full information value of the loss function, but rather relative to the median policy loss obtained when the private sector is learning using the Kalman filter but in the absence of any structural change.

\subsection{Learning about a change in $\bar{r}$}

The (real) natural rate of interest, $\bar{r}$, enters the forward-looking IS curve. In the long run, a permanent change in $\bar{r}$ only has the effect of permanently increasing one-for-one the steadystate nominal interest rate, $\bar{i}$. In the short run, however, changes in $\bar{r}$ make it more difficult for private agents to forecast the output gap and its growth rate. We consider a permanent 1 percentage point (annualized rate) increase in $\bar{r}$ that is unknown to private agents. As earlier, the simulations are initialized with a sample of 200 observations and are replicated 1,000 times to build up a density. Following the increase in $\bar{r}$, we consider 2,000 periods of learning and the results, in the form of estimates of $\bar{\pi}, \bar{r}$, and the implied relative policy loss, are shown in Figure 4. 

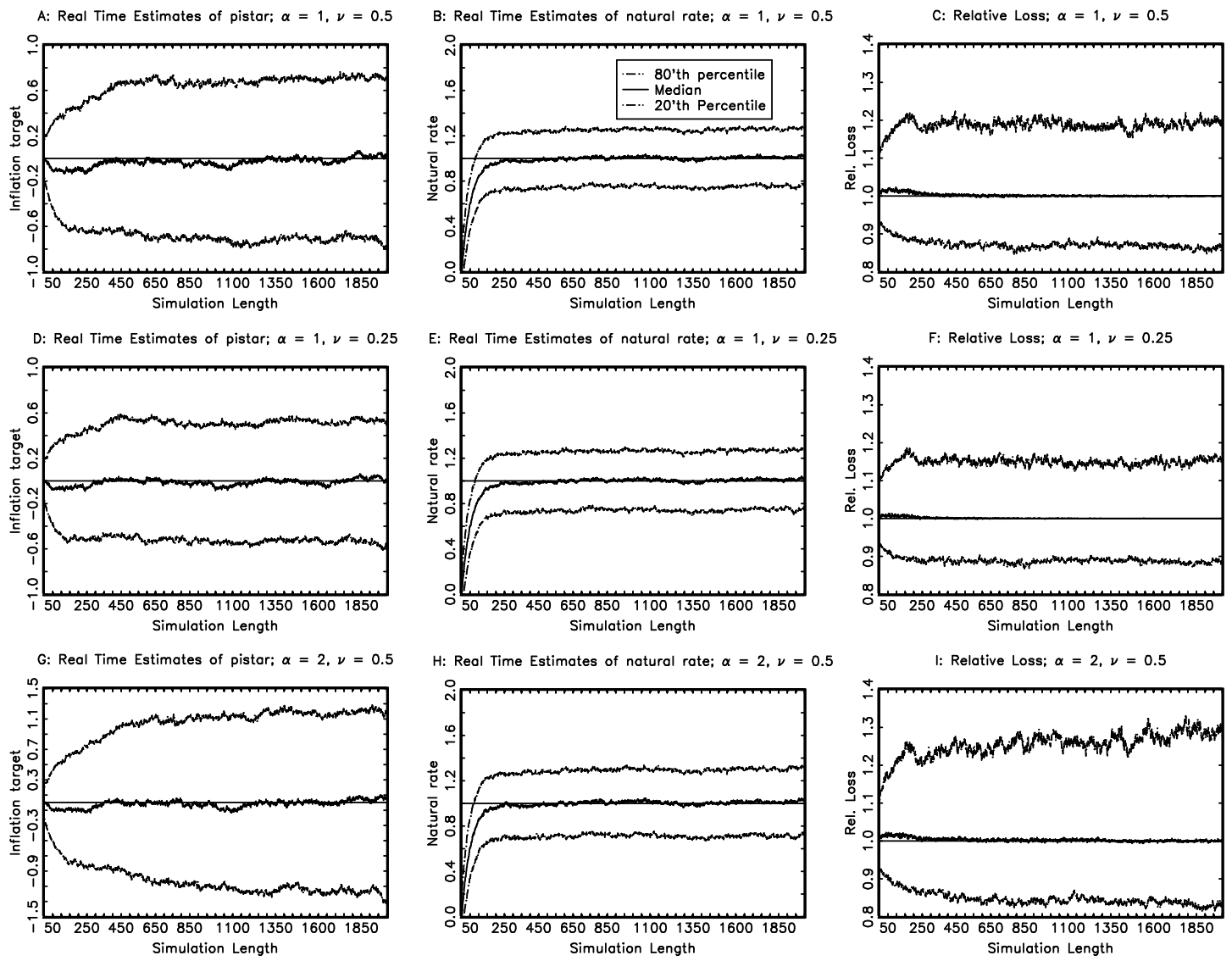

Fig. 4: Private-sector learning about a change in $\bar{r}$

Figure 4 reveals that, although it takes some time for private agents to relearn the natural rate of interest, it takes less than 40 periods to learn 50 percent of the natural rate increase, and the effects of learning are relatively minor. Recalling that $\bar{\pi}$ was set to zero for convenience, panels A, D, and G show that the need for private agents to relearn the natural rate does not materially affect their estimates of the inflation target. Although private agents' estimates of $\bar{\pi}$ are median unbiased, the volatility of the estimates are sensitive to the policy regime. A policy regime that assigns less weight to output stabilization relative to inflation stabilization leads to estimates of the inflation target that are more precise (compare panels A and G). Similarly, a policy regime with less interest rate smoothing also leads to estimates of the inflation target that are more precise (compare panels $\mathrm{A}$ and $\mathrm{D}$ ). With respect to relative loss, the median relative loss converges to one, implying that the central bank's loss following the break in the natural rate converges to the policy loss in the absence of the structural break. Moreover, immediately following the increase in the natural rate of interest, relative loss only rises slightly above one, implying that the need for private agents to relearn the natural rate 
is relatively innocuous, at least in terms of its impact on policy loss.

\subsection{Learning about a change in $\bar{\pi}$}

The inflation target enters both the Phillips curve and the policy rule. As a consequence, the fact that private agents must learn the inflation target and relearn it if it changes can have an important impact on expectations of both future inflation and future interest rates. To see the importance of private-sector learning, and their need to learn the inflation target, consider a one percentage point increase in the inflation target, an increase that is known to the central bank, but not to the private sector. As with the previous experiment, private agents implement their adaptive learning algorithm using the Kalman filter with the gain set to 0.02 . Figure 5 reports the private-sector estimate of the inflation target, the (real) natural rate of interest, and the implied policy loss.

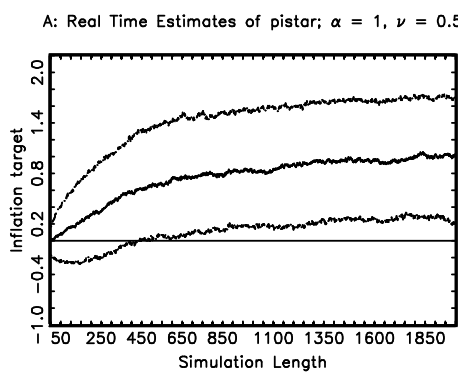

D: Real Time Estimates of pistar; $\alpha=1, \nu=0.25$

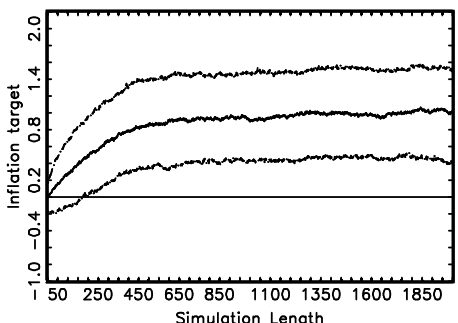

Simulation Length
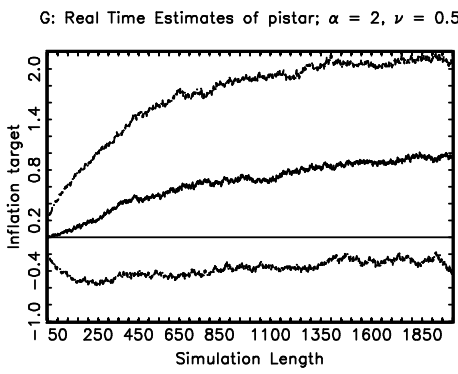

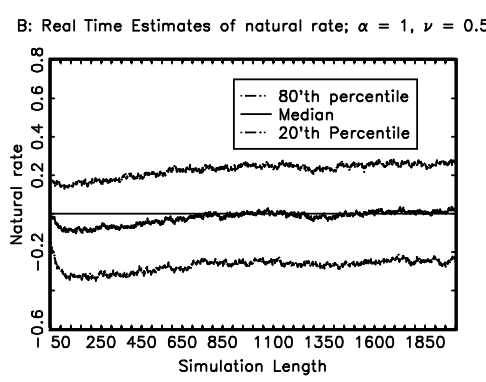

E: Real Time Estimates of natural rate; $\alpha=1, \nu=0.25$

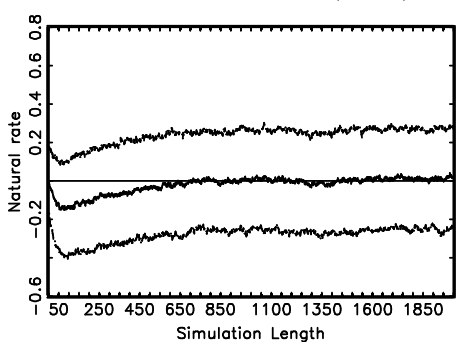

Simulation Length
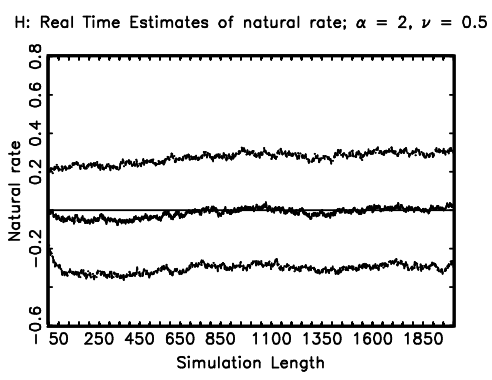

C: Relative Loss; $\alpha=1, \nu=0.5$

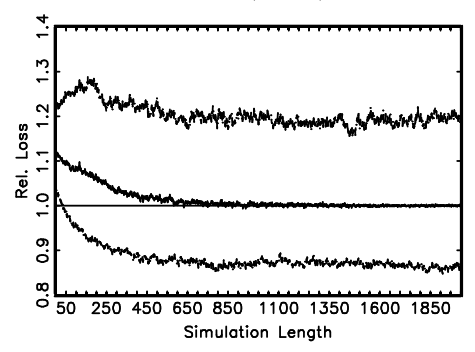

F: Relotive Loss; $\alpha=1, \nu=0.25$

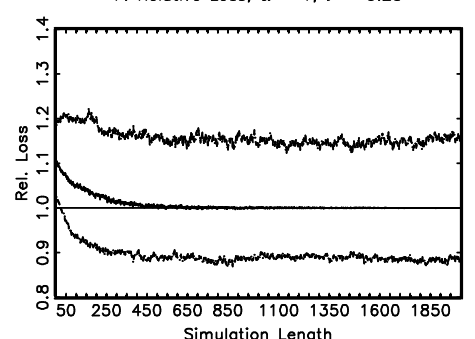

I: Relative Loss; $\alpha=2, \nu=0.5$

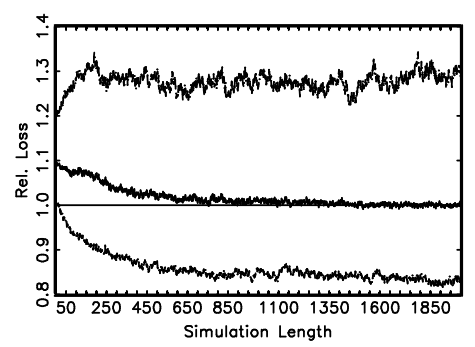

Fig. 5: Private-sector learning about a change in $\bar{\pi}$

Figure 5 reveals three important results. First, it takes a long time for private agents to learn the new value for the inflation target, literally centuries for the calibrations considered. 
However, some policy regimes make it easier for private agents to learn the inflation target than others. Relative to panel A, in which $\alpha=1$ and $\nu=0.5$, panel $\mathrm{D}$, which places less weight on interest rate smoothing, allows private agents to learn the new inflation target more quickly. In contrast, a policy regime that places a high relative weight on output stabilization (panel G) makes it more difficult for private agents to learn. The intuition for these results is quite clear: policy regimes that emphasize inflation stabilization make it easier for private agents to learn the inflation target. Second, while private agents are learning the higher inflation target they tend to underestimate both the inflation target and the natural rate of interest (panels B, E, and $\mathrm{H}$ ) and hence they greatly underestimate the nominal interest rate. Finally, as panels C, F, and I show, the need for private agents to learn the new inflation target has an important impact on relative loss. Following the increase in the inflation target, relative loss rises by as much at 10 percent and remains high for a considerable time. Thus, whereas the need for private agents to learn about a change in the natural rate is largely benign, the need for them to learn about a change in the inflation target is not. As expected, policy regimes that allow private agents to learn the inflation target more quickly - those emphasizing inflation stabilization-lower the cost of learning.

\subsection{Learning following a change in $\alpha$}

The previous section showed that private-sector learning about a change in the inflation target occurs very slowly and that this slow learning rate translates into a large and persistent increase in relative loss. This result provides an incentive for the monetary authority to be transparent about its long-term inflation objective. Indeed many countries have adopted an explicit inflation target to anchor long-term inflation expectations and ease the transition to an economic environment with lower average inflation.

We can use our model to evaluate how private-sector learning about a change in the relative weight placed on output stabilization affects policy loss. ${ }^{14}$ We consider a one-third drop in $\alpha$, the weight on output stabilization relative to inflation stabilization in the objective function. The central bank implements its optimal discretionary targeting rule, which, with $\alpha$ smaller, would imply a lower volatility of inflation in the economy without learning. The private sector must learn about the change in $\alpha$ using its constant-gain algorithm, with the gain set to 0.02 . Figure 6 shows the private sector's real-time estimates of the inflation target, the natural rate

\footnotetext{
${ }^{14}$ Tetlow and von zur Muehlen (2001) perform a similar experiment and find that the welfare loss can be large.
} 
of interest, and the implied relative policy loss.
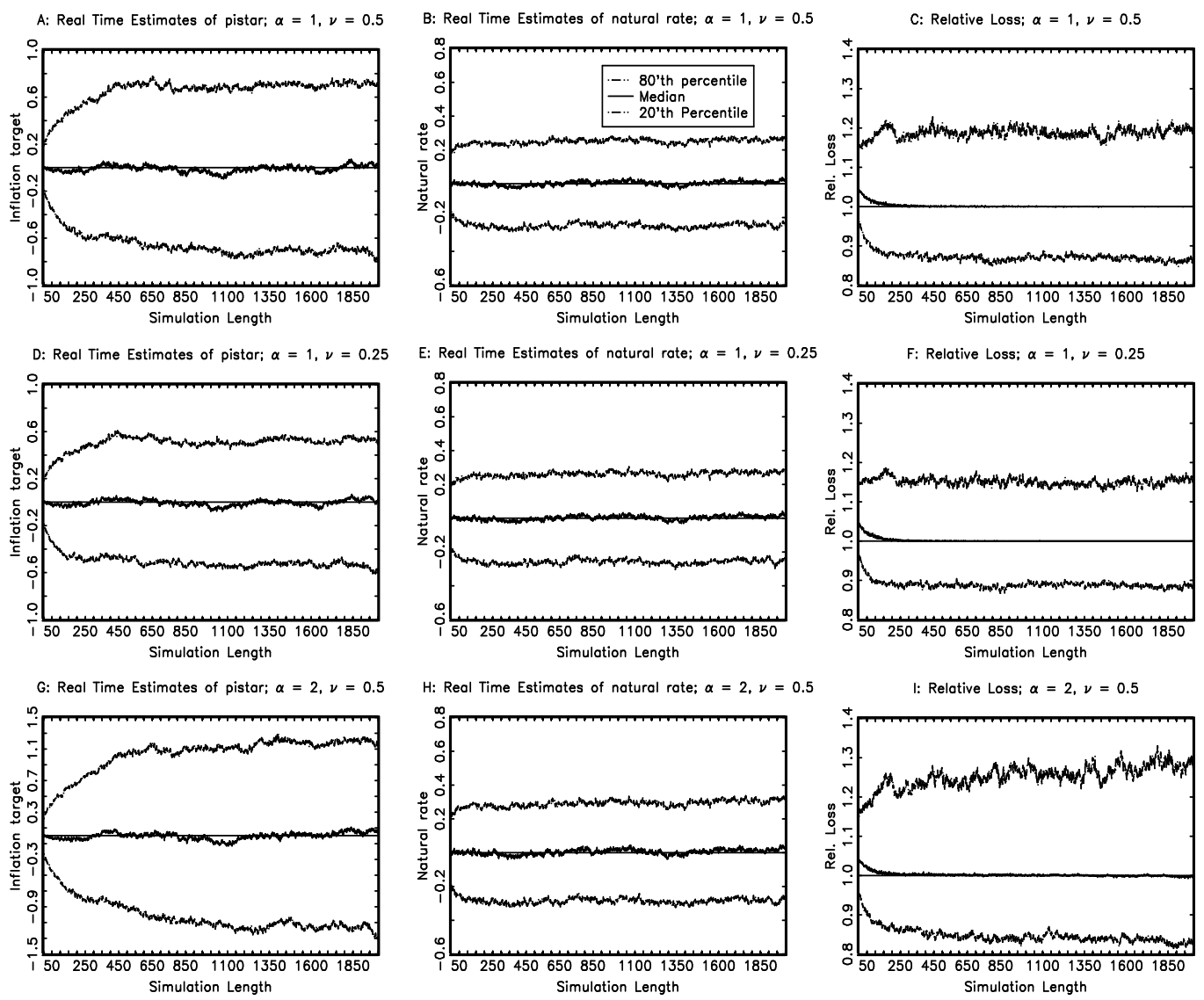

Fig. 6: Private-sector learning following a one-third decline in $\alpha$

The private agents' estimates of $\bar{\pi}$ and $\bar{r}$ are unbiased. Thus, the need for private agents to learn about the change in $\alpha$ does not distort their estimates of the inflation target. Most importantly, learning creates only a moderate temporary worsening in policy loss, which returns to one much faster than when private agents must learn about a change in the inflation target. The different impact on policy loss is explained by the fact that, following a change in the inflation target, the private sector underestimates $\bar{\pi}$ and overestimates the persistence of inflation, which raises policy loss. Although a change in $\alpha$ does affect the rate at which inflation and output will return to target following shocks, the effect of this on the private sector's estimates of inflation and output persistence is much smaller than when there is an unannounced change in the inflation target itself.

Clearly, private agents learning about a change in the inflation target is much more costly than their learning about a shift in the policymaker's preferences, even if in the long run the inflation target is irrelevant to the value of policy loss. An important policy implication that 
follows from this result is that, although transparency about $\alpha$ is desirable, much more can be gained by the central bank being transparent about its inflation target.

\section{Conclusion}

This paper has examined whether central banks can learn to set policy optimally when they are exposed to parameter uncertainty. Inevitably, central banks must formulate policy without knowing the true structure of the economy and this uncertainty can, and should, affect their policies. Although it is clearly desirable for a central bank to be able to learn the economy's underlying structure, the interaction, or feedback, between parameter estimates and economic outcomes that arises when central banks learn means that real-time learnability of the optimal policy is not assured.

To uncover whether optimal policies are real-time learnable and to evaluate the impact of learning on the policymaker's loss, we employed a standard New Keynesian business cycle model, whose behavior is governed by both forward and backward dynamics. Since a central bank must know the economy's structural relationships rather than simply its reduced-form equilibrium relationships to formulate policy, we assumed that the central bank used recursive (generalized) instrumental variables to estimate perceived structural relationships, and studied the real-time learnability of the optimal rational expectations equilibrium when monetary policy was conducted according to an optimal discretionary targeting rule.

Our main results are as follows. Provided the central bank's perceived model is correctly specified, the optimal rational expectations equilibrium and hence the optimal discretionary policy is real-time learnable. This result holds regardless of whether the central bank smooths interest rates or not; however, learning occurs more quickly and is less costly if the central bank does smooth interest rates. Our results also suggest that real-time learnability of the optimal discretionary policy occurs whether the private sector's expectations are rational or are formed using either recursive least squares or a constant-gain learning algorithm. Further, the impact of central-bank learning is small at the median. Although learning occurs slowly, this is largely due to the slow convergence properties of the central bank's learning algorithm and there appears to be little feedback from real-time policymaking to the speed of learning.

While learning occurred slowly, the median cost of deviating from the rational expectations equilibrium was small. Yet, due to sampling variation in the central bank's parameter estimates, the variance in policy loss was large, implying that central-bank learning can have a potentially significant cost. At the same time, strikingly, with policy conducted under discre- 
tion, we found that central-bank learning could actually give rise to an equilibrium loss that improved on the optimal rational expectations equilibrium. This result obtains because the central bank's estimated constraints may lead it to formulate a policy that would be infeasible under discretion given the true constraints. When the private sector is also learning, the likelihood of improved outcomes is even higher. Interestingly, these declines in policy loss are reasonably large and are robust to changes in the monetary policy regime.

We also studied how unannounced changes in the policy regime affect the economy's behavior and policy loss when the private sector is learning. Our results reveal that learning how the policymaker responds to shocks, that is, changes in how the central bank trades off the stability of output and inflation, has only a modest effect on policy loss. Similarly, changes in the natural rate of interest, while detrimental, led to only a relatively small deterioration in policy loss. In contrast, changes to the implicit inflation target that private agents must infer incurs a much higher cost in terms of policy loss. In other words, transparency regarding the inflation target in the policy objective function appears to be much more important for policy loss than transparency regarding how the central bank trades off output stability for inflation stability.

One issue not addressed in this paper is how monetary policy is affected by the distributions of the parameter estimates. In our analysis, once the structural parameters are estimated they are taken to be fixed, clearly a simplifying assumption that could usefully be relaxed. It would also be interesting to allow the central bank to take into account the private-sector learning behavior when formulating its optimal policy (Gaspar, Smets, and Vestin, 2005). Although interesting and clearly relevant for real-time policymaking, both of these issues are left for future work.

\section{A Appendix: Existence of rational expectations equilibrium}

Figure 7 examines the relationships between sample size, the policy regime, and the likelihood of obtaining parameter estimates of $\phi$ and $\lambda$ for which a unique stable rational expectations equilibrium does not exist in environments when only the central bank is learning. We perform 1,000 simulations where each simulation involves 500 periods of real-time policymaking. The reported probabilities are then the proportion of these 1,000 simulations for which nonexistence or indeterminacy is obtained for one or more of the 500 periods. The consistency of the GIV estimator implies that nonexistence of a unique, stable rational expectations equilibrium can be ameliorated by a large initial sample size, but the initial sample size needed may be prohibitively large. 
A: Sample size $=50$

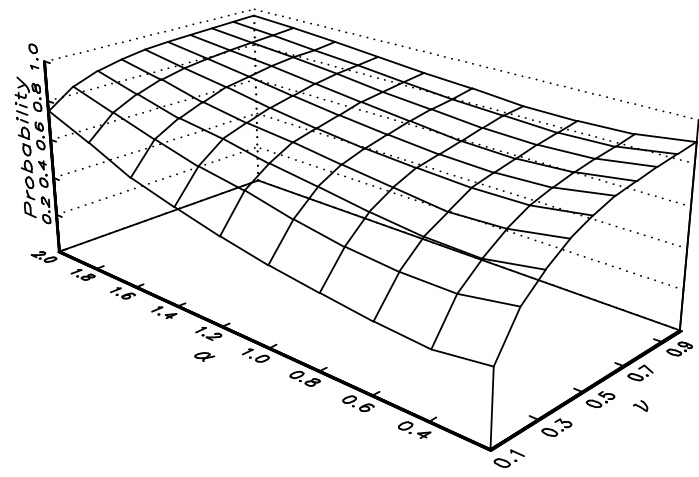

C: Sample size $=200$

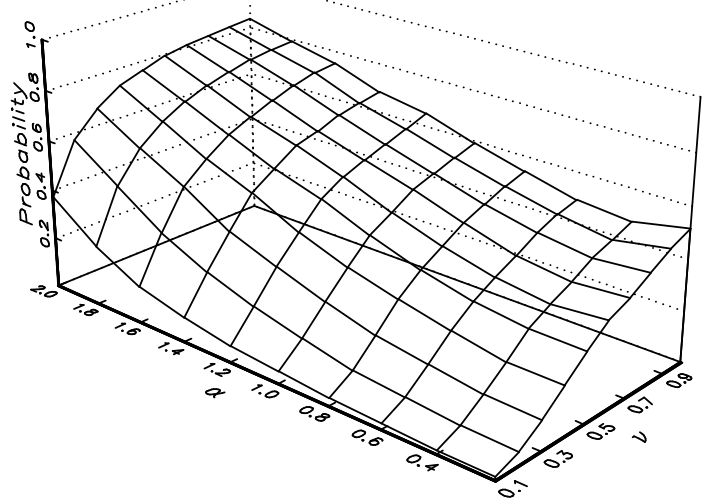

B: Sample size $=100$

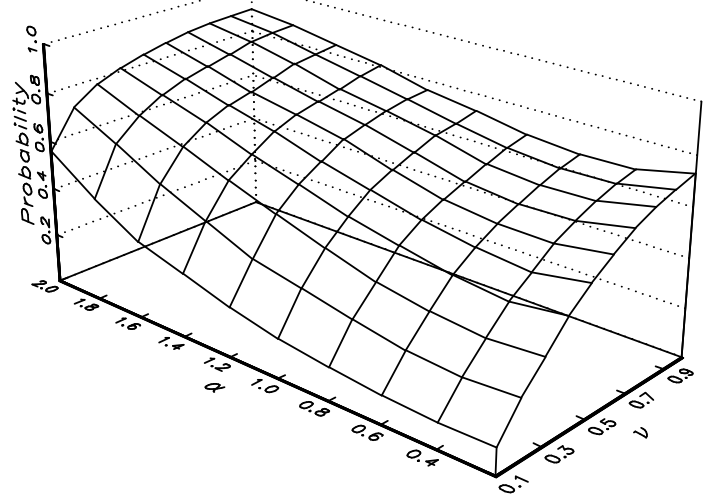

D: Sample size $=300$

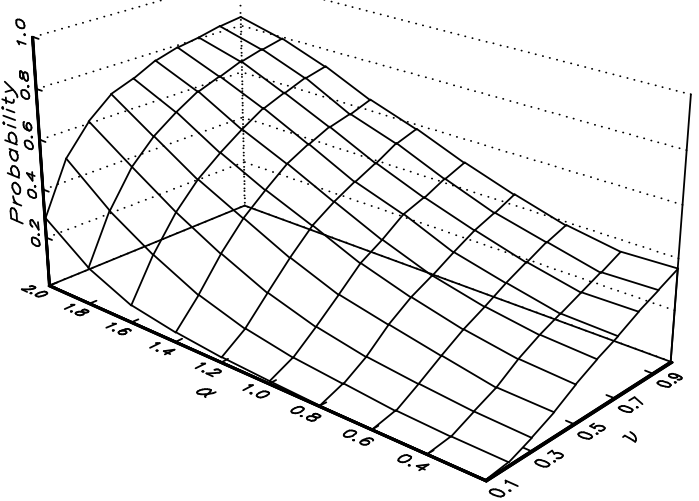

Fig. 7: Probability of unstable or indeterminate RE equilibrium

As might be expected, as we move from panel A to panel $\mathrm{D}$ and the number of initial observations increases from 50 to 300, the probability of obtaining indeterminacy or instability declines. When the sample size is small (panel A), the probability of obtaining instability or indeterminacy is large, simply because the variation in the central bank's GMM estimator is large. However, it is notable that the probability is increasing in both $\alpha$ and $\nu$, implying that policy regimes that focus more directly on stabilizing inflation are more likely to produce a unique stable rational expectations equilibrium. As the sample size increases, while the probability of obtaining instability or indeterminacy declines, it is notable that it declines much more rapidly for policy regimes that focus on stabilizing inflation and less rapidly for policy regimes in which either $\alpha$ (output stabilization) or $\nu$ (interest rate smoothing) are large. This finding is consistent with Orphanides and Williams (2006) who argue that it is advantageous for central banks to place greater weight on inflation stabilization, relative to other goals, when setting policy in uncertain environments.

What happens if $\phi$ and $\lambda$ are varied instead of $\nu$ and $\alpha$ ? The answer is nothing. The reason is that $\phi$ and $\lambda$ are not invariant to the units with which the data are measured, so changes to $\phi$ and $\lambda$ amount to a rescaling of the data. Consequently, while the central bank's estimates of $\phi$ and $\lambda$ rise proportionately with changes in $\phi$ and $\lambda$, the central bank's targeting rule and the model's behavior are unaffected.

\section{References}

[1] Aoki, K. and Nikolov, K., 2004. Rule-based monetary policy under central bank learning, in: Clarida, R., Frankel, J. and Giavazzi, F. (Eds.), International Seminar in Macroeconomics Conference Proceedings. National Bureau of Economic Research, Boston. 
[2] Amato, J., Laubach, T., 2004. Implications of habit formation for optimal monetary policy. Journal of Monetary Economics 51, 305-325.

[3] Ball, L., 1999. Efficient rules for monetary policy. International Finance 2, 63-83.

[4] Bullard, J., Mingitra, K., 2002. Learning about monetary policy rules. Journal of Monetary Economics 49, 1105-1129.

[5] Calvo, G., 1983. Staggered contracts in a utility-maximising framework. Journal of Monetary Economics 12, 383-398.

[6] Christiano, L., Eichenbaum, M., Evans, C., 2005. Nominal rigidities and the dynamic effects of a shock to monetary policy. Journal of Political Economy 113, 1-45.

[7] Clarida, R., Galí, J., Gertler, M., 1999. The science of monetary policy: a New Keynesian perspective. Journal of Economic Literature 37, 1661-1707.

[8] Cogley, T., Sargent, T., 2005. The conquest of U.S. inflation: learning and robustness to model uncertainty. Review of Economic Dynamics 8, 528-563.

[9] Dennis, R., 2007. Optimal policy in rational expectations models: new solution algorithms. Macroeconomic Dynamics 11, 31-55.

[10] Dennis, R., Söderström, U., 2006. How important is commitment for monetary policy? Journal of Money, Credit, and Banking 38 (4), 847-872.

[11] Evans, G., Honkapohja, S., 2001. Learning and Expectations in Macroeconomics. Princeton University Press, Princeton.

[12] Evans, G., Honkapohja, S., 2003a. Expectations and the stability problem for optimal monetary policies. Review of Economic Studies 70, 807-824.

[13] Evans, G., Honkapohja, S., 2003b. Adaptive learning and monetary policy design. Journal of Money, Credit, and Banking 35, 1045-1072.

[14] Evans, G., Honkapohja, S., 2006. Monetary policy, expectations and commitment. Scandinavian Journal of Economics 108, 15-38.

[15] Ferrero, G., 2007. Monetary policy, learning and the speed of convergence. Journal of Economic Dynamics and Control 31, 3006-3041.

[16] Galí, J., Gertler, M., 1999. Inflation dynamics: a structural econometric analysis. Journal of Monetary Economics 44, 195-222.

[17] Gaspar, V., Smets, F., Vestin, D., 2005. Optimal monetary policy under adaptive learning. Mimeo, European Central Bank.

[18] Giannoni, M., Woodford, M., 2005. Optimal inflation targeting rules, in: Bernanke, B., Woodford, M. (Eds.), The Inflation Targeting Debate. University of Chicago Press, Chicago.

[19] Kydland, F., Prescott, E., 1977. Rules rather than discretion: the inconsistency of optimal plans. Journal of Political Economy 87, 473-492.

[20] Levin, A., Onatski, A., Williams, J., Williams, N., 2006. Monetary policy under uncertainty in micro-founded macroeconometric models, in: Gertler, M., Rogoff, K. (Eds.), NBER Macroeconomics Annual 2005. MIT Press, Cambridge, pp. 229-287. 
[21] Levin, A., Williams, J., 2003. Robust monetary policy with competing reference models. Journal of Monetary Economics 50, 945-975.

[22] Levin, A., Wieland, V., Williams, J., 2003. The performance of forecast-based monetary policy rules under model uncertainty. American Economic Review 93, 622-645.

[23] Marcet, A., Sargent, T., 1989. Convergence of least squares learning mechanisms in self referential linear stochastic models. Journal of Economic Theory 48, 337-368.

[24] McCallum, B., Nelson, E., 1999. Nominal income targeting in an open-economy optimizing model. Journal of Monetary Economics 43, 553-578.

[25] Orcutt, G., Winokur, H., 1969. First order autoregression: inference, estimation, and prediction. Econometrica 37, 1-14.

[26] Orphanides, A., Williams, J., 2005. Imperfect knowledge, inflation expectations, and monetary policy, in: Bernanke, B., Woodford, M. (Eds.), The Inflation Targeting Debate. University of Chicago Press, Chicago.

[27] Orphanides, A., Williams, J., 2006. Inflation targeting under imperfect knowledge. Federal Reserve Bank of San Francisco Economic Review, 1-23.

[28] Rotemberg, J., 1982. Monopolistic price adjustment and aggregate output. Review of Economic Studies 49, 517-531.

[29] Sargent, T., 1999. The Conquest of American Inflation. Princeton University Press, Princeton.

[30] Smets, F., Wouters, R., 2003. An estimated stochastic dynamic general equilibrium model of the Euro Area. Journal of the European Economic Association 1, 1123-1175.

[31] Svensson, L., 1997. Inflation forecast targeting: implementing and monitoring inflation targets. European Economic Review 41, 1111-1146.

[32] Svensson, L., Woodford, M., 2005. Implementing optimal policy through inflation-forecast targeting, in: Bernanke, B., Woodford, M. (Eds.), The Inflation Targeting Debate. University of Chicago Press, Chicago.

[33] Tetlow, R., von zur Muehlen, P., 2001. Simplicity versus optimality: the choice of monetary policy rules when agents must learn. Journal of Economic Dynamics and Control $25,245-279$.

[34] Walsh, C., 2005. Parameter misspecification and robust monetary policy rules. European Central Bank Working Paper \#477.

[35] Wieland, V., 2000. Learning-by-doing and the value of optimal experimentation. Journal of Economic Dynamics and Control 24, 501-534.

[36] Woodford, M., 2003. Interest and Prices. Princeton University Press, Princeton. 